\title{
EL NUEVO PROTOCOLO DE PRETORIA SOBRE GARANTÍAS INTERNACIONALES EN EQUIPO MINERO, AGRÍCOLA Y DE CONSTRUCCIÓN: LA FUERZA EXPANSIVA DEL CONVENIO DE CIUDAD DE CABO
}

\author{
THE NEW PRETORIA PROTOCOL ON INTERNATIONAL \\ INTERESTS IN MINING, AGRICULTURAL, AND \\ CONSTRUCTION EQUIPMENT: THE EXPANSIVE FORCE \\ OF THE CAPE TOWN CONVENTION
}

\author{
Teresa Rodríguez de las Heras Ballell* \\ Profesora titular de Derecho mercantil \\ Universidad Carlos III de Madrid
}

Recibido: 22.06.2020 / Aceptado: 01.07.2020

DOI: https://doi.org/10.20318/cdt.2020.5625

\begin{abstract}
Resumen: El 22 de noviembre de 2019, en la ciudad sudafricana de Pretoria, se adoptó el cuarto Protocolo al Convenio de Ciudad del Cabo sobre garantías internacionales en equipo móvil. Con la adopción del Protocolo de Pretoria, el exitoso sistema uniforme de Ciudad del Cabo (Convenio y Protocolos) se extiende, de acuerdo con su peculiar fórmula de delimitación del ámbito de aplicación, a los sectores agrícola, minero y de construcción. Con ello, el sistema de Ciudad del Cabo muestra una extraordinaria fuerza expansiva gracias a la maleabilidad de sus soluciones, la flexibilidad que le confiere su original estructura modular (Convenio-Protocolos) y, sobre todo, el potencial armonizador de un modelo de base sectorial, sensible a las diversas tradiciones jurídicas, pero contundente en la formulación de conceptos autónomos y soluciones uniformes, y cercano a las prácticas de financiación del sector, adecuado a las características de los equipos y consistente con las necesidades del mercado. Este trabajo ofrece un análisis detallado y en profundidad del Protocolo de Pretoria, desde su elaboración hasta su aprobación, en el contexto del sistema de Ciudad el Cabo al que pertenece, desde esta perspectiva del equilibrio entre consistencia y flexibilidad, entre la necesidad de buscar fórmulas innovadoras y adaptadas a las nuevas necesidades de los sectores minero, agrícola y de construcción y mantener la coherencia con las soluciones vertebrales del Convenio y la lógica material y operativa subyacente.

Palabras clave: Garantías internacionales, equipo minero, agrícola y de construcción, leasing, Convenio de Ciudad del Cabo, reserva de dominio

Abstract: On November 22, 2019, in the South African city of Pretoria, a fourth Protocol to the Cape Town Convention on International Interests in Mobile Equipment was adopted. The adoption of the Pretoria Protocol entails the expanding of the successful Cape Town system, as per the singular

*Experta del Study Group constituido por UNIDROIT (International Institute for the Unification of Private Law, Roma) para la redacción de un cuarto protocolo al Convenio de Ciudad del Cabo sobre garantías internacionales sobre equipo móvil minero, agrícola y de construcción (Protocolo de Pretoria o Protocolo MAC). Delegada de España ante UNIDROIT en las dos sesiones del Comité de Expertos Gubernamentales para la aprobación del Protocolo MAC celebradas en Roma (sede de la FAO), primera sesión en marzo de 2017 y segunda sesión en octubre de 2017. Delegada de España en la Conferencia Diplomática para la adopción del Protocolo MAC que tuvo lugar en Pretoria (Sudáfrica) del 11 al 22 de noviembre de 2019, como Asesora Externa de Asesoría Jurídica Internacional (AJI). En este artículo la autora expresa y recoge sus opiniones y no actúa bajo representación institucional alguna.
\end{abstract}


scoping formula, to the mining, agricultural, and construction industries. Thus, the Cape Town system proves an extraordinary expansive force thanks to malleable solutions, a flexible modular structure (Convention-Protocol), and, fundamentally, the harmonizing potential of its sector-specific approach, sensitive to legal traditions, but conclusive in formulating autonomous concepts and uniform solutions; and close to sectoral financing practices, suited to characteristics of equipment, and consistent with market needs. This Paper aims to provide a thorough and in-depth analysis of the Pretoria Protocol, from its elaboration to its final adoption, in the context of the Cape Town system, it belongs to, from the perspective of the balance between consistency and flexibility, the advisability to devise innovative formulae better adapted to the targeted sectors, and the need to maintain consistency with the foundational solutions of the Convention and its material and operational logic.

Keywords: International interests, mining, agricultural and construction equipment, leasing, Cape Town Convention, title reservation.

Sumario: I.- La fuerza expansiva del Convenio de Ciudad del Cabo sobre garantías internacionales en equipo móvil. II.- Adaptabilidad y consistencia del sistema de Ciudad del Cabo: el equilibrio logrado en el Protocolo de Pretoria. 1.Las bases de la adaptabilidad del sistema de Ciudad del Cabo. A) La estructura modular del sistema de Ciudad del Cabo facilita su expansión material. B) La formulación de conceptos uniformes y autónomos confiere maleabilidad a las soluciones del Convenio. C) La sensibilidad a las tradiciones jurídicas y la cercanía al mercado garantizan su adaptabilidad. 2. La necesidad de consistencia y las razones para la formulación de soluciones innovadoras en el Protocolo de Pretoria. III.- El ámbito de aplicación del Protocolo de Pretoria. 1. El criterio de internacionalidad y las transacciones internas. 2. El domicilio del deudor y la irrelevancia de la situación del bien. 3. La singular fórmula de delimitación del ámbito de aplicación objetivo en el Protocolo de Pretoria: los bienes mineros, agrícolas y de construcción. A). La decisión de adoptar un único Protocolo para tres sectores. B). El recurso al Sistema Armonizado de la Organización Mundial de Aduanas para la delimitación de las categorías de bienes. C). La interacción del Protocolo de Pretoria con Protocolos previos. D). La adaptación del Protocolo de Pretoria a las revisiones del Sistema Armonizado: revisiones, ajustes y modificaciones. 4.- El tratamiento de partes y componentes y el principio de accesión. IV.- El Protocolo de Pretoria en el contexto del sistema de Ciudad del Cabo: consistencia con la lógica, los principios y las soluciones del Convenio. 1. Puntos de interacción, complementariedad y coordinación entre el Protocolo de Pretoria y la legislación nacional. 2.Continuidad y consistencia con los Protocolos previos y algunos ajustes y novedades del Protocolo de Pretoria. A). La nueva declaración en el Artículo VIII sobre remedios en caso de incumplimiento. B). La eliminación de alternativas en el Artículo X sobre remedios en caso de insolvencia. C). Los puntos nacionales de acceso al Registro Internacional. V.- Las soluciones innovadoras del Protocolo de Pretoria: financiación de inventario y equipos asociados a bienes inmuebles.1. De la movilidad a la asociación con bienes inmuebles. 2. De la financiación sobre activos a la financiación de inventario.

\section{La fuerza expansiva del Convenio de Ciudad del Cabo sobre garantías internacionales en equi- po móvil}

1. El 22 de noviembre de 2019, en la ciudad sudafricana de Pretoria, se adoptó el cuarto Protocolo al Convenio de Ciudad del Cabo sobre garantías internacionales en equipo móvil ${ }^{1}$, conocido como Protocolo MAC, por el acrónimo de los bienes cubiertos (mineros, agrícolas y de construcción) por el nuevo instrumento, y, tras su aprobación, también como Protocolo de Pretoria, como tributo y reconocimiento al país anfitrión (en adelante, alternativamente, Protocolo MAC o Protocolo de Pretoria)².

\footnotetext{
${ }^{1}$ El Convenio fue adoptado en la Conferencia diplomática celebrada en Ciudad del Cabo (Sudáfrica), de la que ha tomado su habitual denominación como Convenio de Ciudad del Cabo, entre los días 29 de octubre y 16 de noviembre de 2001, bajo los auspicios de UNIDROIT (International Institute for the Unification of Private Law / Institut International pour l'Unification du Droit Privé) y de la Organización de Aviación Civil Internacional (OACI/ICAO). El texto oficial del Convenio en español disponible en https://www.unidroit.org/official-languages-si-conv/spanish-siconv-pdf.

${ }^{2}$ La Conferencia Diplomática para la adopción del cuarto Protocolo del Convenio de Ciudad del Cabo (Protocolo MAC o Protocolo de Pretoria) se celebró en Pretoria (Sudáfrica) los días 11 a 22 de noviembre de 2019. La Conferencia Diplomática concluyó satisfactoriamente con la adopción del Protocolo, la apertura a la firma y ratificación y su firma ya por cuatro Estados en el
} 
2. Con la adopción del Protocolo de Pretoria, el ambicioso sistema uniforme conformado por el Convenio de Ciudad del Cabo y sus Protocolos extiende su perímetro de acción más allá de los sectores inicialmente previstos - aeronáutico, espacial y ferroviario - para incorporar ahora, de conformidad con su peculiar fórmula de delimitación del ámbito de aplicación, las industrias agrícola, minera y de construcción. Con ello, el sistema de Ciudad del Cabo muestra una extraordinaria fuerza expansiva que apalanca en el éxito logrado en el sector aeronáutico con su primer Protocolo. En efecto, el mapa de ratificaciones del Convenio y el Protocolo Aeronáutico refleja una amplia aceptación internacional y muestra una muy significativa y equilibrada participación de países con economías y tradiciones jurídicas diversas. Los más de 80 Estados que son ya parte ${ }^{3}$ del Convenio ${ }^{4}$ avalan el acierto de las soluciones uniformes del instrumento internacional y la efectividad de las respuestas para aliviar los fallos del mercado del crédito ${ }^{5}$ facilitar el acceso a la financiación en condiciones razonables para la adquisición y el uso de equipos móviles de alto valor.

mismo acto final de clausura de la Conferencia. De acuerdo con el Informe Final presentado el día 21 de noviembre por el Comité de Credenciales (DCME-MAC - Doc. 37), la Conferencia Diplomática contaba con la participación de 41 Estados, registrados como participantes, una organización regional de integración económica (REIO) - la Unión Europea -, 3 organizaciones intergubernamentales, 4 organizaciones internacionales no gubernamentales y un asesor técnico. El presente trabajo hace referencia a la documentación puesta a disposición de las delegaciones antes y durante la Conferencia Diplomática a través de la plataforma dedicada https://macprotocol.info/. Los informes diarios de las sesiones, los informes provisionales y finales de todos los comités, las resoluciones finales y el acta final, así como la versión previa del borrador de Protocolo y el texto final del Protocolo MAC tras su adopción, están disponibles también en abierto en la misma plataforma. Así mismo, la plataforma dedicada al Protocolo (https://macprotocol.info/) ofrece información detallada sobre el proceso de elaboración del Protocolo (Grupo de Expertos y Comité de Expertos Gubernamentales), sus principales hitos y el desarrollo de las sesiones de la Conferencia Diplomática.

${ }^{3}$ El empleo de los términos "Estado Parte" y "Estado Contratante" en el texto se utiliza de conformidad con el uso y significado que le confieren el Convenio de Ciudad del Cabo y los Protocolos. Este uso difiere del uso internacional de ambos términos. El Convenio de Viena sobre Derecho de los Tratados de 23 de mayo de 1969 proporciona las siguientes definiciones:

Artículo 2 - Términos empleados

${ }^{1}$ A los efectos del presente Convenio

(f) se entiende por "Estado contratante" un Estado que ha consentido en obligarse por el tratado, haya o no entrado en vigor el tratado

(g) se entiende por "parte" un Estado que ha consentido en obligarse por el tratado y con respecto al cual el tratado está en vigor"

El uso del término "Estado Contratante" en el sistema de Ciudad del Cabo es equivalente a "Estado Parte". Este uso inverso se discutió por el Study Group en sus reuniones durante la elaboración del Protocolo MAC, pero la necesidad de mantener coherente con el Convenio y la conveniencia de alinearse con los Protocolos previos aconsejaron mantener este uso. Así también lo advierte, Karl F. KReuzer, "Jurisdiction and choice of law under the Cape Town Convention and the Protocols thereto", Cape Town Convention Journal, 2:1, 2013, pp. 149-164, en p. 150.

${ }^{4}$ Según datos de fecha 4 de septiembre de 2020, el Convenio cuenta con 81 Estados contratantes (más la Unión Europea como Organización Regional de Integración Económica), mientras que en el Protocolo Aeronáutico ascienden a 78 más la Unión Europea. Ambos textos están conjuntamente en vigor desde el 1 de marzo de 2006. Se puede consultar el estado de las ratificaciones (aceptaciones, aprobaciones o adhesiones), las declaraciones realizadas por los Estados, así como la entrada en vigor de cada uno de los instrumentos, en www.unidroit.org (Instruments/Security Interests/Status), seleccionando cada uno de los instrumentos que se desea consultar.

${ }^{5}$ La capacidad del sistema de garantías para reducir los riesgos, mejorar las condiciones y estimular la oferta de crédito se explica, desde una perspectiva económica, por su potencial para reparar o, al menos, atenuar los fallos que aqueja el mercado de la financiación: información asimétrica, riesgo moral, y selección adversa - S.D. WiLLIAMSON, "Costly monitoring, loan contracts, and equilibrium credit rationing", Quarterly Journal of Economics, vol. 102, issue 1, 1987, pp. 135-145 -. En contradicción con los modelos teóricos de competencia perfecta, compradores y vendedores no disponen de información perfecta, completa, equivalente ni objetiva sobre los servicios y productos del mercado, objeto de sus transacciones. El origen de las situaciones de información imperfecta se puede localizar en tres fuentes: la falta de información sobre el riesgo, el desconocimiento de las alternativas disponibles en el mercado, y la ignorancia de las condiciones contractuales. Las asimetrías de información reflejan aquellas situaciones en las cuales una de las partes de la transacción dispone de información a la cual, la otra parte tan sólo podría acceder asumiendo un coste o, incluso, para quien es inaccesible. J.E. STIGLITZ.; A. Weiss, "Credit rationing in markets with imperfect information", American Economic Review, vol. 71, num. 3, 1981, pp. 393-410; O.E. WiLliamson, "The Economics of Antitrust: Transactions Costs Considerations", 122 U. Pa. L. Rev., 1973-1974, pp. 1439-1496. La dificultad que acusa el financiador para obtener información fiable sobre la solvencia del deudor y la viabilidad del proyecto que presenta, debido a la marcada asimetría de información, se atenúa al suplir la necesidad de esta información por la valoración directa e inmediata de la garantía prestada. El riesgo moral se gestiona adaptando el valor de la garantía al importe del préstamo, sin asumir el coste social que implica el lento proceso de ajuste de acuerdo con la información histórica de cumplimiento del deudor. Y, frente al riesgo de comportamientos oportunistas, la petición de garantías mejora las condiciones de los préstamos y reduce el impacto 
3. Esta fuerza expansiva del sistema de Ciudad del Cabo ha demostrado la maleabilidad de sus soluciones, la flexibilidad que le confiere su original estructura modular (Convenio-Protocolos) y, sobre todo, el potencial armonizador de un modelo de base sectorial, sensible a las diversas tradiciones jurídicas, pero contundente en la formulación de conceptos autónomos y soluciones uniformes, y cercano a las prácticas de financiación del sector, adecuado a las características de los equipos y consistente con las necesidades del mercado. Pero a la vez, la expansión del Convenio a estos nuevos sectores, diversos en multitud de aspectos a los rasgos comunes que identificaban el núcleo inicial de su ámbito de aplicación material (equipo aeronáutico, espacial y ferroviario), ha puesto a prueba la consistencia del sistema, la adaptabilidad de sus soluciones a entornos diversos y la coherencia de las nuevas fórmulas innovadoras del Protocolo MAC con la lógica del sistema de Ciudad del Cabo y sus principios fundamentales.

4. Este trabajo ofrece un análisis detallado y en profundidad del Protocolo de Pretoria en el contexto del sistema de Ciudad el Cabo al que pertenece, desde esta perspectiva del equilibrio entre consistencia y flexibilidad, entre la necesidad de buscar fórmulas innovadoras y adaptadas a las nuevas necesidades de los sectores minero, agrícola y de construcción y mantener la coherencia con las soluciones vertebrales del Convenio y la lógica material y operativa subyacente (infra II). A partir de este análisis global del sistema uniforme desde la tensión entre flexibilidad y solidez, adaptabilidad y consistencia, se centra la atención en el Protocolo de Pretoria como ejemplo ilustrativo del equilibrio logrado entre ambas variables. A tal fin, se destacarán, en particular, las soluciones más innovadoras con las que el Protocolo de Pretoria logra acomodar las disposiciones del Convenio de Ciudad del Cabo a las prácticas de financiación con garantía sobre activos (asset-based finance) para la adquisición y el uso de equipos mineros, agrícolas y de construcción, preservando la lógica de los principios, los conceptos y las soluciones clave del sistema uniforme en el que se integra. Primero, con un minucioso estudio de la original fórmula empleada para delimitar el ámbito de aplicación del Protocolo de Pretoria en el marco de y consistente con la lógica material del sistema de Ciudad del Cabo (infra III). Segundo, con un repaso general de aquellos elementos del sistema uniforme que se han mantenido, con algunas adaptaciones, en el nuevo Protocolo (infra IV). Y, finalmente, con la presentación de aquellas soluciones enteramente novedosas y diseñadas a medida de las peculiaridades de los sectores de referencia, las prácticas de la industria, y las características de los equipos agrícola, minero y de construcción que el proceso de elaboración del Protocolo de Pretoria ha debido contemplar y su texto final tras la adopción así contiene (infra $\mathrm{V})$.

\section{Adaptabilidad y consistencia del sistema de Ciudad del Cabo: el equilibrio logrado en el Pro- tocolo de Pretoria}

\section{Las bases de la adaptabilidad del sistema de Ciudad del Cabo}

5. El potencial expansivo del modelo armonizador implementado por el Convenio de Ciudad del Cabo tiene sus bases en un alto nivel de adaptabilidad del sistema. Esta capacidad de adaptación se fundamenta esencialmente en tres rasgos característicos del sistema de Ciudad del Cabo: su estructura modular (Convenio-Protocolos), la maleabilidad de sus soluciones basadas en conceptos autónomos y uniformes, y su cercanía y receptividad a las tradiciones jurídicas, de un lado, y a las prácticas y necesidades del mercado, de otro.

\footnotetext{
de la selección adversa al proporcionar al acreedor una ruta para la recuperación de la deuda, alternativa al éxito del proyecto, del que el prestatario puede no tener mucha información - H. BESTER, "The role of collateral in credit markets with imperfect information”, European Economic Review, núm. 31, 1987, pp. 887-899; Y-S. CHAN; G. KANATAS, "Asymmetric valuations and the role of collateral in loan agreements", Journal of Money, Credit and Banking, vol. 17, 1985, pp. 84-95; H.W. FLeISIG, "The economics of collateral and of collateral reform", en F. Dahan; J. Simpson (Eds.), Secured Transactions Reform and Access to Credit, Cheltenham (UK): Edward Elgar, 2008, pp. 81-109, p. 86; K. IGAWA; G. Kanatas, "Asymmetric information, collateral, and moral hazard", Journal of Financial and Quantitative Analysis, vol. 25 (4), 1990, pp.469-49 -.
} 


\section{A) La estructura modular del sistema de Ciudad del Cabo facilita su expansión material}

6. El primero de los rasgos referidos es de carácter estructural y describe la original fórmula organizativa sobre la que el Convenio de Ciudad del Cabo expande su ámbito de aplicación. Consiste en una original estructura modular y en dos niveles ${ }^{6}$. El sistema se compone, en un primer nivel, de un cuerpo único de normas generales contenidas en el Convenio y, en un segundo nivel, de un conjunto de disposiciones específicas para cada categoría de elementos de equipo móvil que se van articulando en diversos Protocolos. El carácter modular del sistema se despliega a través de los Protocolos con los que el Convenio interactúa, no bajo una relación de subordinación propia de un desarrollo reglamentario, sino como dos piezas complementarias que conforman conjuntamente, en cada caso, el Convenio aplicable a la categoría de objetos correspondiente. Así, en efecto, cada Protocolo contiene reglas específicas para la categoría de elementos de equipo móvil a la que se aplica - que pueden ampliar, alterar o derogar las reglas generales del Convenio -, determina la entrada en vigor del Convenio en relación con tal categoría de bienes y define exactamente el ámbito de aplicación, de modo que, en caso de discordancia entre las disposiciones del Convenio y las del Protocolo, prevalecen las de este último por su especificidad.

7. La estructura en dos niveles del sistema y su operativa modular han sido, sin duda, uno de los factores coadyuvantes de su éxito y facilitador hoy de su expansión. La decisión, a lo largo del proceso de elaboración, de desvincular la formulación de las normas generales de las disposiciones específicas para cada categoría de elementos de equipo móvil permitió que la negociación se desarrollara a ritmos diferentes, atendiendo a las particularidades de cada sector e interactuando con la industria. De ese modo, el proceso pudo concluir con éxito con la adopción en 2001 del Convenio y el Protocolo Aeronáutico.

8. Como consecuencia de este original sistema de Convenio-Protocolos, el Convenio no puede operar independientemente de sus Protocolos, ni tampoco naturalmente podría hacerlo un Protocolo sin la cobertura del Convenio. Convenio y Protocolo, de hecho, conforman conjuntamente un único instrumento que ha de interpretarse como tal (Art. 6.1 Convenio). El Convenio define originariamente su ámbito de aplicación en relación con tres categorías de objetos (Art. 2.3.) pero no entra en vigor con respecto a una determinada categoría de elementos de equipo (Art. $49.1^{7}$ ) hasta que se haya adoptado el Protocolo correspondiente y además lo hace con sujeción a las disposiciones de dicho Protocolo. De modo que, el Convenio, en relación con el equipo aeronáutico y sólo para tal categoría de bienes, (conjuntamente con el Protocolo Aeronáutico) entró en vigor el 1 de marzo de 2006. Una vez en vigor, conforme al Artículo 49.2 Convenio, para cada Estado Contratante entrará en vigor únicamente respecto a las categorías de objetos a las cuales se aplica el o los Protocolos que el Estado haya ratificado, se haya adherido, aceptado o aprobación y con sujeción a dicho/s Protocolo/s.

9. Los Protocolos relativos a las tres categorías de bienes originariamente definidas en el Convenio (Artículo 2.3) ya han sido adoptados - Protocolo sobre cuestiones específicas de los elementos de equipo aeronáutico, el 16 de noviembre de 2001, que entró en vigor el 1 de marzo de 2006 (Protocolo Aeronáutico); Protocolo sobre material rodante ferroviario, el 23 de febrero de 2007 (en adelante, Protocolo Ferroviario o de Luxemburgo); Protocolo sobre bienes de equipo espacial, el 9 de marzo de 2012

\footnotetext{
${ }^{6}$ Que explico y describo con más detalle en T. RodríGuez de las Heras Ballell, Las garantías mobiliarias sobre equipo aeronáutico en el comercio internacional. El Convenio de Ciudad del Cabo y su Protocolo, Marcial Pons, Madrid, 2012, pp. 28 y ss.

${ }^{7}$ Artículo 49.1 del Convenio:

"El presente Convenio entrará en vigor el primer día del mes siguiente a la expiración de un período de tres meses posterior a la fecha de depósito del tercer instrumento de ratificación, aceptación, aprobación o adhesión, pero únicamente respecto a las categorías de objetos a las cuales se aplica un Protocolo:

a) a partir del momento de entrada en vigor de ese Protocolo;

b) con sujeción a las disposiciones de dicho Protocolo; y

c) entre los Estados que son partes en el presente Convenio y en dicho Protocolo."
} 
(en adelante, Protocolo Espacial) -, si bien, de conformidad con el Artículo 49 del Convenio, sólo el Protocolo Aeronáutico está actualmente en vigor ${ }^{8}$.

10. Apoyado en esta estructura modular que evita la fosilización del instrumento originariamente adoptado y le permite acomodarse, sin alterar el núcleo inicial, a nuevos sectores, el sistema de Ciudad del Cabo se ve dotado de un extraordinario potencial de expansión. Esta capacidad expansiva tan sólo tiene los límites que marca el Artículo 51 del Convenio, que encapsula la lógica misma del sistema: el establecimiento de un régimen jurídico uniforme para las operaciones de financiación con garantía sobre activos para la adquisición y el uso de ciertos equipos móviles, de alto valor y susceptibles de identificación única. Estos rasgos trazan el perímetro exterior de todo intento de expansión del Convenio de Ciudad del Cabo a otros elementos de equipo móvil, más allá de las tres categorías de bienes expresamente mencionados en el Artículo 2.3: equipo aeronáutico, bienes de equipo espacial y material rodante ferroviario.

11. Esta es la fórmula sobre la que se apoya la decisión de elaborar un cuarto Protocolo para extender el Convenio a tres nuevas categorías de bienes: mineros, agrícolas y de construcción. Así, en 2014, el UNIDROIT Governing Council convino9, tras la consecución de estudios y consultas previas ${ }^{10}$, crear un Study Group ${ }^{11}$ para discutir y elaborar un posible cuarto Protocolo para elementos de equipo en los sectores minero, agrícola y de construcción que, tras las deliberaciones y los cambios realizados por el Comité de Expertos Gubernamentales en sus dos sesiones, fue sometido a negociación y finalmente adopción en la Conferencia Diplomática ${ }^{12}$.

12. Bajo la cobertura del Artículo 51, el sistema de Ciudad del Cabo podrá seguir expandiéndose, con futuros Protocolos, a otros sectores para la financiación del uso y la adquisición de equipos que satisfagan los criterios de identificabilidad, elevado valor y movilidad ${ }^{13}$.

\section{B) La formulación de conceptos uniformes y autónomos confiere maleabilidad a las soluciones del Convenio}

13. El segundo de los rasgos que confieren un alto grado de adaptabilidad al sistema de Ciudad el Cabo es la decisión de política legislativa de conformar un régimen jurídico internacional basado en la formulación de conceptos autónomos y soluciones uniformes. En efecto, el objetivo del Convenio es establecer un régimen uniforme aplicable a los acuerdos de garantía sobre ciertas categorías de bienes

\footnotetext{
${ }^{8}$ Para consultar el estado de las ratificaciones (aceptaciones, aprobaciones o adhesiones), así como la entrada en vigor de cada uno de los instrumentos, se puede acceder a www.unidroit.org (Instruments/Security Interests/Status).

${ }^{9}$ El Consejo acordó la constitución de un grupo de estudio para la elaboración del proyecto de Protocolo en su 93 ${ }^{\mathrm{a}}$ sesión. El proyecto de Protocolo se aprobó en la $95^{\mathrm{a}}$ sesión, mayo 2016. En diciembre 2016, se celebró un Simposio para la presentación por la Secretaría y el Study Group del borrador del texto con la participación de 16 Estados miembros.

${ }^{10}$ El proyecto se adoptó en el Programa de Trabajo de UNIDROIT en 2005. En 2006 se preparó un primer estudio preliminar sobre la viabilidad del Protocolo MAC y se consultó a los Estados, recibiendo apoyo en términos generales. En 2009 y 2010, se llevaron a cabo consultas con la industria (Alemania y Estados Unidos). El estudio preparado por el Center for the Economic Analysis of Law (CEAL) en 2012/2013 estimó que un futuro cuarto Protocolo podría incrementar las ventas de este tipo de equipo hasta 600 Millones de USD en un periodo de 5 a 7 años e incrementar el PIB global en 3 trillones de USD.

${ }^{11}$ La autora de este trabajo ha sido miembro del Study Group junto con los profesores Mooney, Riffard, Von Bondungen, y Michel Deschamps. Todos los materiales de las reuniones, los borradores del texto, los informes solicitados y remitidos, y las versiones anotadas del Protocolo están disponibles en https://www.unidroit.org/mac-protocol-preparatory-work.

${ }^{12}$ Los días 20 a 24 de marzo de 2017 se celebró en Roma la primera sesión del Comité de Expertos Gubernamentales (CEG1) sobre el Protocolo MAC y los días 2 al 6 de octubre del mismo año la segunda sesión (CEG2) que adoptó el texto del Protocolo que se presentó para la discusión de los Estados en la Conferencia Diplomática como borrador para su negociación y adopción. Las reuniones del CGE contaron con la asistencia de 128 participantes de 48 países y 11 organizaciones internacionales.

${ }^{13}$ O. BöGER, "The case for a new Protocol to the Cape Town Convention covering security over ships", Cape Town Convention Journal, vol. 5:1, 2016, pp. 73-102.
} 
de significativa importancia económica e inherente movilidad (equipo aeronáutico, material rodante ferroviario, bienes espaciales, según lo inicialmente previsto) para facilitar la financiación de la adquisición y uso de tales equipos en condiciones eficientes. Las operaciones de financiación garantizada sobre activos en un contexto internacional acusan apreciables dificultades añadidas a la propia complejidad de la transacción derivadas, de un lado, de la disparidad en el tratamiento jurídico y la propia concepción de las diversas fórmulas de garantías en el Derecho Comparado y, de otro, de las dificultades para su reconocimiento y eficacia asociadas a la inscripción en registros locales y el efecto inadecuado de las normas de conflicto basadas en la res sitae. Estos efectos obstaculizadores se agravan de forma particular en sectores intensivos en capital y fuertemente dependientes del crédito, donde los bienes, de alto valor económico, son además inherentemente móviles por su propia naturaleza y las operaciones son naturalmente transfronterizas. Por tal motivo, la iniciativa armonizadora de UNIDROIT acierta al decidir concentrar los esfuerzos de unificación normativa en varios sectores específicos (concretamente, aeronáutico, ferroviario y espacial, $\mathrm{y}$, en proceso, minero, agrícola y de construcción) para poder atender sus concretas necesidades de financiación.

14. El Convenio debía pues lidiar con dos problemas. De un lado, armonizar soluciones y elaborar reglas uniformes ante la patente disparidad en el tratamiento jurídico y la propia concepción de las diversas fórmulas de garantías en el Derecho Comparado. De otro lado, gestionar esta divergencia de enfoques jurídicos en las operaciones transfronterizas en relación con bienes de equipo de inherente movilidad o débil conexión territorial (objetos aeronáuticos, material rodante ferroviario, equipo espacial). Para ello, se crea un concepto autónomo, unitario y funcional de garantía internacional ${ }^{14}$ para el que se establece un marco uniforme de sencillas reglas de prioridad, remedios para los casos de incumplimiento y medidas ante supuestos de insolvencia y se constituye un sistema registral propio para asegurar la oponibilidad a terceros e instrumentar el régimen de prioridad. Estas son las tres piezas clave del sistema: una pieza conceptual; una pieza sustantiva, y una pieza adjetiva o registral.

15. Primero, la creación de un concepto autónomo, unitario y funcional ${ }^{15}$ de "garantía internacional" que agrupa un conjunto de esquemas contractuale ${ }^{16}$ con función de garantía (garantías mobiliarias, ventas con reserva de dominio, arrendamientos) para los que establece un conjunto de reglas uniformes sobre constitución, medidas en caso de incumplimiento, efectos de las garantías en caso de insolvencia y prioridad. Por tanto, el Convenio se apoya en la construcción funcional de un concepto sui generis de "garantía internacional" que permite la aplicación de las reglas uniformes sobre constitución, efectos y prioridad a diversos esquemas contractuales con función de garantía sobre activos (asset-based): acuerdos de garantía, leasing, arrendamiento, o compraventa con reserva de dominio. La original fórmula de armonización empleada por el Convenio consistente en diseñar un concepto autónomo de garantía internacional de base funcional; es decir, un concepto que agrupa y trata unitariamente diferentes esquemas contractuales en virtud de la función común que desempeñan e independientemente de la forma jurídica que adoptan. Se prima así la "intención" y la "sustancia" sobre la "forma" 17 . El empleo de esta estrategia, denominada funcionalista, en el contexto de las legislaciones nacionales sobre garantías mobiliarias retoma un delicado debate entre tradiciones jurídicas en el Derecho Comparado que se puede condensar en el conflicto "funcionalismo versus formalismo".

${ }^{14}$ R. Goode, “The International Interest as an Autonomous Property Interest”, European Review of Private Law, vol. 12, num.1, 2004, pp. 18-25.

${ }^{15}$ T. RodrígueZ de las Heras Ballell, "El concepto funcional de garantía en el Convenio de Ciudad del Cabo relativo a garantías internacionales sobre elementos de equipo móvil”, Anuario de Derecho Civil, tomo LXV, 2012, fasc. IV, pp. 1605-1652.

16 A.M. Garro, "El concepto genérico, global e integrado de «garantía mobiliaria»: perspectivas comparadas", en Ch. Larroumet (Ed.) L'èvolution des garanties mobilières dans les droits français et latino-américains, Paris, Panthéon-Assas, 2016, pp. 87-99.

${ }^{17}$ Con esta contraposición entre "forma" y "sustancia" se resume el debate, aún abierto, entre "funcionalismo" y "formalismo" al que nos referimos más adelante en este trabajo. M.G. Bridge; R.A. Macdonald; R.L. Simmonds; C. WaLSh, "Formalism, Functionalism, and Understanding the Law of Secured Transactions", 44 McGill Law Journal, 1998-1999, pp. 567-664. 
16. Segundo, por tanto, la formulación de un cuerpo de reglas sustantivas uniformes aplicables a las garantías internacionales sobre constitución, oponibilidad, prioridad, acciones del acreedor en caso de incumplimiento y tratamiento de la garantía en caso de insolvencia.

17. Tercero, el diseño de un Registro Internacional para cada categoría de objetos que permite la inscripción de las "garantías internacionales" (y otros derechos y situaciones inscribibles) para conferirles oponibilidad frente a terceros y articular las reglas de prioridad. Sintéticamente ${ }^{18}$ se puede describir el sistema registral de Ciudad del Cabo como un Registro electrónico de carácter internacional, estructurado mediante el sistema de folio real, para la inscripción no constitutiva de determinados derechos y garantías sobre determinadas categorías de bienes identificables de forma única con preferencia de rango ordenada por prioridad cronológica, con eficacia frente a terceros con independencia de la buena fe y a cargo de un Registrador "pasivo" que no lleva a cabo calificación registral; de consulta universal on-line, y sin aportación documental - notice-filing (o más precisamente modelo notice registry o notice registration ${ }^{19}$ ) -. En el estado actual de desarrollo del sistema de Ciudad del Cabo, el Registro Internacional para objetos aeronáuticos es el único en funcionamiento y se encuentra plenamente operativo. De hecho, la dependencia de las reglas sustantivas del Convenio/Protocolo del sistema registral exige una plena coordinación entre la entrada en vigor del Protocolo y la puesta en marcha del Registro correspondiente ${ }^{20}$.

\section{C) La sensibilidad a las tradiciones jurídicas y la cercanía al mercado garantizan su adaptabilidad}

18. Finalmente, hay un tercer rasgo característico del Convenio que completa el diagnóstico de su adaptabilidad. Son algunos de los principios que vertebran el sistema uniforme y que inspiran la formulación, interpretación y aplicación de las soluciones ${ }^{21}$. En particular, la orientación y el sentido práctico de las disposiciones, el protagonismo de la autonomía de la voluntad, y la sensibilidad a las tradiciones jurídicas.

19. Las soluciones del Convenio están concebidas desde la observación del mercado y con una aportación sustancial de la industria en su valoración y formulación ${ }^{22}$. Durante la elaboración y poste-

${ }^{18}$ Un estudio detallado del Registro Internacional en T. RodríGUEZ DE LAS HERAs BALLELL, Las garantías mobiliarias sobre equipo aeronáutico en el comercio internacional. El Convenio de Ciudad del Cabo y su Protocolo, Marcial Pons, Madrid, 2012, en Capítulo II.

${ }^{19}$ Precisa acertadamente R.C.C. Cuming, "Considerations in the design of an International Registry for Interests in Mobile Equipment”, Uniform Law Review, 1999-2, pp. 275-288, en p. 275 que el término filing pertenece a un escenario precisamente de aportación documental en el que se "archivan" los documentos presentados, mientras que en un entorno electrónico como el del Registro Internacional es más correcto emplear la expresión registration en la medida que el sistema registral se basa en "registros o anotaciones electrónicas". En el particular caso del Registro Internacional para elementos de equipo aeronáuticos, es además un modelo notice-based dada la mínima información susceptible de inscripción registral.

${ }^{20}$ En la Resolution No. 1 of the Luxembourg diplomatic Conference on 23 February 2007 se constituye una Comisión Preparatoria (Preparatory Commission - Rail PrepCom) para la puesta en funcionamiento del Registro Internacional para material rodante ferroviario. En 2014 se designa y concluye el acuerdo con Regulis SA (filial de SITA) para la gestión del registro.

En la Resolution 1 relating to the setting up of the Preparatory Commission for the establishment of the International Registry for Space Assets, Anexo II del Acta Final de la Conferencia Diplomática de Berlín, UNIDROIT 2012 - DCME - SP Doc. 43, se fija un plazo de tres años desde la adopción del Protocolo el 9 de marzo de 2012 para la puesta en funcionamiento del sistema registral y la entrada en vigor del Protocolo espacial. En la sesión de diciembre de 2015, la Comisión Preparatoria (Space PrepCom) constituida con este objetivo finaliza la elaboración del Reglamento del Registro. En esta misma sesión se abordó la selección de la entidad encargada del registro y la designación de Autoridad de Supervisión.

${ }^{21}$ No hay un catálogo de principios en el Convenio, pero de los fines enunciados en el preámbulo y de sus disposiciones se extrae un conjunto de principios que explica Sir Roy Goode en Official Commentary. Revised Edition. Convention on International Interests in Mobile Equipment and Protocol Thereto on Matters Specific to Aircraft Equipment, third edition, Roma: Unidroit, 2013, par. 2.17, p. 22.

${ }^{22}$ El proceso de elaboración del Protocolo desde su inicio cuenta, en todo momento, con las aportaciones de la industria. Cada uno de los Protocolos se elabora en paralelo a la constitución de un Working Group que representa a la industria. Así, el Protocol MAC, contó en todo momento con el impulso de la industria, representada por el MAC Working Group, y venía avalado por la experiencia en otros sectores, trasladada a la Comisión por el Aviation Working Group, el Rail Working Group, y el International Registry para equipo aeronáutico. 
rior implementación de todos los Protocolos del Convenio de Ciudad del Cabo, la visión de la industria ha sido fundamental para asegurar que el Convenio y los Protocolos respondían de forma eficiente y adecuada a las necesidades del mercado, a las prácticas de financiación, y los requerimientos de cada sector. Para ello, se han ido constituyendo, en relación con cada Protocolo, un vehículo (denominado Working Group) que agrupa a los stakeholders del sector privado, coordina la respuesta de la industria, participa en la elaboración del Protocolo, y canaliza todas las opiniones del sector ${ }^{23}$. Por tanto, con utilidad o sentido práctico, el Convenio se esfuerza en reflejar adecuadamente las necesidades reales y las características específicas de las operaciones de financiación garantizadas con activos y los contratos de arrendamiento con igual propósito, con un estilo pragmático que refuerza su capacidad adaptativa.

20. En coherencia con un contexto transaccional de relaciones transfronterizas, equipos de elevado valor o gran importancia económica, y operadores experimentados y debidamente asesorados, la autonomía de la voluntad tiene un marcado protagonismo en el sistema uniforme, lo que, con ciertos límites, deja igualmente vías abiertas de adecuación y modulación de las soluciones a los intereses de las partes.

21. Finalmente, y, sobre todo, el Convenio se construye sobre un equilibrio entre la sensibilidad a las diversas tradiciones legales nacionales, para facilitar su ratificación, y la aspiración de la máxima armonización posible, que requiere minimizar las desviaciones interpretativa y las excepciones nacionales y reforzar la unificación de las soluciones. Este complicado equilibrio se articula mediante una red de declaraciones bien definida en relación con las disposiciones donde la divergencia del Derecho Comparado era mayor y la unificación de las soluciones menos viable, y una sugerente fórmula "circular" 24 que impacta en cómo se opera en la práctica el concepto mismo de garantía internacional. En efecto, de acuerdo con el Artículo 2 del Convenio, el concepto de garantía internacional se diseña como un concepto paraguas que abarca garantías que derivan de diversos contratos (contrato constitutivo de garantía, contrato de venta con reserva de dominio, contrato de arrendamiento) y que, por tanto, puede recibir una diferente calificación según las tradiciones jurídicas (derecho de garantía mobiliaria, derecho de propiedad). La calificación de la garantía es relevante a los efectos de la determinación de los remedios que el acreedor puede ejecutar en caso de incumplimiento conforme a tales contratos se deja a la legislación nacional. El Convenio ofrece dos conjuntos de remedios cuyo ejercicio dependerá de cómo resulta calificado el acuerdo de garantía por la legislación nacional. Así, mientras que dos extensas disposiciones (Artículos 8 y 9) detallan las medidas aplicables al acreedor garantizado, una sucinta provisión (Artículo 10) condensa los sencillos remedios disponibles para el vendedor condicional o el arrendador. Esta diferente extensión de los artículos dedicados en cada caso refleja claramente que, en realidad, el vendedor condicional y el arrendador en la medida que sean tratados como propietarios, les corresponden las facultades absolutas propias de esta condición. Pero será el Derecho interno el que confirme o discrepe con esta ecuación y sus resultados. Por tanto, si la ley nacional aplicable califica el contrato con reserva de dominio como un contrato de garantía y equipara así la posición del vendedor condicional a la de un acreedor garantizado, se aplicarán las medidas establecidas en los artículos $8 \mathrm{y}$ 9 y no las del artículo 10.

23 A tal fin, se han creado:

- El Aviation Working Group (AWG) - http://www.awg.aero/ - cuyos miembros son http://www.awg.aero/inside-awg/ members/

- El Rail Working Group (RWG) - https://www.railworkinggroup.org/ - del que la autora es miembro (https://www.railworkinggroup.org/about-us/members/).

- El MAC Working Group (MACWG) - https://www.macwg.org/ que representa a asociaciones y empresas del sector: fabricantes, entidades de leasing y financieras, distribuidoras en los sectores de minería, agricultura y construcción.

Para impulsar la adopción de los Protocolos y posteriormente facilitar la implementación del instrumento internacional en aquellos Estados Contratantes que lo han ratificado, los Working Groups han diseñado una red de National Contact Groups para proporcionar información local, estar en contacto con la industria, actuar como facilitadores e identificar áreas de especial interés práctico para la industria.

${ }^{24}$ Una calificación que explico y expongo en otros trabajos previos. En particular, y como referencia, T. RoDRÍGUEZ DE LAS Heras Ballell, "The accession by Spain to the Cape Town Convention: a first assessment", Uniform Law Review - Revue de droit uniforme 2014; DOI: https://doi.org/10.1093/ulr/unu004, pp. 1-23, en p. 18. 


\section{La necesidad de consistencia y las razones para la formulación de soluciones innovadoras en el Protocolo de Pretoria}

22. Todas las razones anteriores avalan la adaptabilidad del sistema de Ciudad del Cabo y confirman su potencial expansivo para extender sus beneficios a otros sectores. Por ello, el punto de partida y el método con el que se trabajó en todo momento desde el Study Group fueron elaborar el Protocolo MAC siguiendo la estructura, la lógica y los principios de los protocolos previos (Aeronáutico ${ }^{25}$, Espa$\mathrm{cial}^{26}$, y Ferroviario ${ }^{27}$ ), y limitando así las desviaciones de las soluciones previas a aquellos casos que las especificidades de los sectores y de los objetos así lo han requerido.

23. El resultado de esta opción legislativa con la adopción del Protocolo de Pretoria ofrece, por tal motivo, un ilustrativo modelo de prueba para valorar la solidez de los principios del sistema de Ciudad del Cabo y la maleabilidad de sus principales soluciones. Pero, a la vez, ha implicado la superación de algunos desafíos que han requerido un esfuerzo creativo y de adaptación ${ }^{28}$ del esquema del Convenio y los Protocolos previos, que se analizan con detalle a continuación (infra II y IV, en especial), y que se concentran esencialmente en tres grandes áreas.

24. El primero de los retos, fundamental para la conformación del texto normativo y crítico para el éxito del proyecto, era la delimitación del ámbito de aplicación objetivo. Encontrar la fórmula que de manera precisa y adecuada permitiera la determinación de las categorías de bienes sujetos al régimen uniforme e implementarla de forma que resultara previsible, clara y efectiva en su aplicación era una decisión básica, que presentó, sin embargo, una notable complejidad ${ }^{29}$. La necesidad de idear un mecanismo adecuado de delimitación del ámbito de aplicación del texto internacional era clave para dotar de seguridad jurídica y previsibilidad a las partes contratantes en la negociación y conclusión de sus operaciones de financiación con garantía sobre activos; así como para los terceros interesados en verificar la existencia de una garantía internacional y su prioridad mediante consulta en el Registro Internacional.

25. Pero, además, la delimitación de los bienes susceptibles de quedar sujetos a las reglas del Protocolo tenía que asegurar una perfecta alineación con dos criterios que articulan la interacción del régimen internacional con la legislación nacional y con otros instrumentos uniformes. Primero, la expansión del ámbito de aplicación debe ser consistente con el Artículo 51 del Convenio que define la filosofía del sistema de Ciudad del Cabo conforme a las características de los bienes: movilidad, alto valor e identificación única. Segundo, esta concreción de las categorías de bienes implica, en realidad, una lógica de interacción del régimen internacional con la legislación doméstica y de compatibilidad con otros instrumentos armonizadores. En definitiva, la relación entre el sistema uniforme y la legislación nacional se basa en la identificación de aquellas operaciones de financiación para la adquisición y el uso de ciertas categorías de bienes en las que los problemas regulatorios, derivados de la inadecuación de la

${ }^{25}$ T. Rodríguez de las Heras Ballell, "Las operaciones internacionales de financiación garantizada sobre equipo aeronáutico: el Convenio de Ciudad del Cabo y su Protocolo", en M. Alba Fernández; A. Fortes Martín (Dirs.), Público y Privado en el Derecho Aeronáutico: Retos presentes y futuros, Valencia, Tirant lo Blanch, 2016, pp. 171-208.

${ }^{26}$ T. Rodríguez de las Heras Ballell, "La financiación garantizada para la adquisición y el uso de satélites y otros bienes de equipo espacial”, Derecho de los Negocios, núm. 265-266, noviembre 2012, pp. 21-47.

${ }_{27}$ T. Rodríguez de las Heras Ballell, "El Protocolo de Luxemburgo al Convenio de Ciudad del Cabo: financiación para uso y adquisición de material rodante ferroviario", A-L Calvo Caravaca; I. Tirado Martí (Eds.), Unidroit y la Codificación Internacional de Derecho Privado, Valencia, Tirant lo Blanch, 2020, pp. 291-330.

${ }^{28}$ T. Rodríguez de las Heras Ballell, "Complexities arising from the expansion of the Cape Town Convention to other sectors: the MAC Protocol's challenges and innovative solutions", Uniform Law Review, Volume 23, Issue 2, June 2018, pp. 214-241.

${ }^{29}$ Dada la complejidad de esta cuestión se discutió con intensidad en los foros internacionales de expertos - H.D. GABRIEL, “The MAC Protocol: We Aren't There Yet - How Far Do We Have To Go?", Cape Town Convention Journal, Volume 4, Issue 1, 2015, pp. 67-75, en pp. 69 y 70, en particular - y se trató con mucha atención y cuidado en el Study Group para asegurar que la fórmula propuesta era la adecuada en su concepción y en su operativa - Ch.W.Jr. Mooney, "The MAC Protocol: some comments and a challenge”, Cape Town Convention Journal, Volume 4, Issue 1, 2015, pp. 76-82, pp. 79 y 79, en concreto -. 
lex situs, y económicos (sectores intensivos en capital, naturaleza cíclica, estructura competitiva, complejidad técnica, alto valor de los bienes) $)^{30}$, se presentan con especial severidad y, por tanto, la necesidad de armonización resulta particularmente intensa y acuciante en un contexto naturalmente transfronterizo con una marcada divergencia entre los sistemas nacionales ${ }^{31}$. Este acuerdo de compatibilidad entre regímenes jurídicos es especialmente crítico porque el sistema de Ciudad del Cabo puede aplicarse no sólo a las típicas transacciones internacionales (con partes contratantes en diferentes países), sino también a transacciones que podrían ser calificadas tradicionalmente como puras operaciones domésticas o internas. Esto se logra con una interesante y original concepción de la "internacionalidad", que se presume inherente a la movilidad, real o potencial, de los objetos a los que se aplica. Por ello, es especialmente crítica la adecuada definición de las categorías de bienes para legitimar la necesidad del régimen uniforme sobre la respuesta nacional.

26. Por otro lado, los criterios del alto valor y la movilidad, de un lado, y el carácter identificable de forma única de los equipos, de otro, facilitan además una relación de complementariedad entre el sistema de Ciudad del Cabo y otros instrumentos internacionales de armonización. Así, en particular, la Ley Modelo de CNUDMI sobre Garantías Mobiliarias, como referencia de un instrumento de armonización genuinamente internacional, prevé la coordinación con el sistema de Ciudad del Cabo en la implementación por los Estados de procesos de reforma o modernización de su legislación interna conforme a la Ley Modelo ${ }^{32}$. Los Estados podrán decidir (Artículo 1.3, letra e) ) $^{33}$ que la ley de garantías mobiliarias que adopten no se aplique a determinadas garantías mobiliarias por razón del objeto. Entre las exclusiones, la Ley Modelo se refiere a ciertos bienes sujetos a regímenes de garantía especiales y a un modelo registral de inscripción del objeto (asset-based registration regimes) que el Estado debería especificar de forma clara en la ley interna para articular la coordinación con estos regímenes especializados. Este

\footnotetext{
${ }^{30}$ Con respecto a la industria aeronáutica, A. SAunders; A. SRinivasan; I. Walter; J. Wool, "The Economic Implications of International Secured Transactions Law Reform: A Case Study", 20 University of Pennsylvania Journal of International Economic Law, 1999, pp. 309-352.

${ }^{31}$ La actual heterogeneidad conceptual y normativa parece tener sus raíces en la diferente acogida en el siglo XIX de las figuras del Derecho Romano - W.J. ZwALZE, "A Labyrinth of Creditors: a short introduction to the history of security interests in goods", en E.-M. KIENInger, Security Rights in Movable Property in European Private Law, Cambridge, Cambridge University Press, 2004, pp. 38-53 -. Tal divergencia de actitudes se acentúa entre los sistemas del common law, que muestran una tendencia más orientada a los acreedores, y los del civil law, más propensos a atender las necesidades de los deudores - R. GoodE, "The Changing Nature of Security Interests", en J.J. NorTon; M. AndenAs (Ed.), Emerging Financial Markets and Secured Transactions, London, Kluwer Law International, 1998, pp. 1-4 -. Una incomprensión mutua que parte de la diversidad, casi incompatibilidad, de principios en materia de transmisión de la propiedad y se extiende a toda la disciplina de las garantías mobiliarias - U. Drobnig, "Transfer of Property", en A. HartKamp et al. (Ed.), Towards a European Civil Code, Nijmegen, Kluwer Law International, 2004, pp. 725-740; U. DrobNIG, "A Comparative Introduction to Security over Movables and Intangibles", en J.J. Norton; M. ANDENAS (Ed.), Emerging Financial Markets and Secured Transactions, London, Kluwer Law International, 1998, pp. 5-13; y en la misma obra, P.R. WooD, "World-wide Security-classification of Legal Jurisdictions", pp. 39-47 -. Esta divergencia de principios puede sintetizarse en los siguientes juegos de variables: funcionalismo-formalismo, tipicidad-atipicidad de los derechos reales; principio de causalidad-principio de abstracción; prohibición o admisión del pacto comisorio; principio de publicidad-garantías ocultas.

${ }^{32}$ En el mismo sentido, la Ley Modelo de la OEA sobre Garantías Mobiliarias facilita esta coordinación con el sistema de Ciudad del Cabo al prever regímenes especiales para ciertas categorías de objetos con un registro especializado. De modo que, si bien la implementación de la Ley Modelo regional no es un requisito previo para la adhesión al Convenio y sus Protocolos, su eventual adopción no sólo no dificulta, sino que, de hecho, asiste al Estado Contratante en la coordinación de los textos y facilita la operativa del instrumento internacional. J. Feliu Rey y T. Rodríguez de las Heras Ballell, "La Ley Modelo Interamericana sobre Garantías Mobiliarias en el contexto de la armonización internacional de las reglas relativas a las garantías reales sobre bienes muebles", en D. Morán Bovio (Dir.), Ley Modelo Interamericana sobre Garantías Mobiliarias: su implementación, Madrid, Marcial Pons - OEA, 2020, pp. 31-42; J.M. Wilson, "Movable Equipment Financing in Latin America: Application of the OAS Model Law, the Cape Town Convention and the Luxembourg Rail Protocol", Unif. L. Rev., num. 12, 2007, pp. 473-487, en p. 479.

33 Artículo 1.3 Ley Modelo:

"Sin perjuicio de lo dispuesto en el párrafo 1, la presente Ley no será aplicable a las garantías mobiliarias que graven: (...)

e) Los demás tipos de bienes que indique el Estado promulgante, como los que estén sujetos a regímenes especiales de operaciones garantizadas e inscripción registral basada en los bienes con arreglo a otra ley, en la medida en que esa otra ley rija las cuestiones previstas en la presente Ley".
} 
modelo registral basado en la inscripción del objeto es una referencia clara al sistema de Ciudad del Cabo, frente al modelo de inscripción del deudor que vertebra la Ley Modelo.

27. La Ley Modelo proporciona esencialmente un modelo normativo para la reforma o modernización de la legislación interna del Estado promulgante, mientras que el Convenio de Ciudad del Cabo responde a las necesidades de las operaciones internacionales de financiación. Sin embargo, la singular concepción de la internacionalidad en el Convenio que habilita la aplicación del texto uniforme a las transacciones puramente internas hace posible, en tal sentido, el solapamiento con la Ley Modelo, amplia y abarcadora en su ámbito de aplicación. El cumplimiento de los criterios materiales que articulan el sistema de Ciudad del Cabo resolvería el solapamiento con una solución de compatibilidad y coordinación de ámbitos de aplicación.

28. Se analiza a continuación (infra III) con detenimiento la fórmula elegida, pragmática y original, para delimitar el ámbito de aplicación objetivo del Protocolo de Pretoria mediante el recurso al Sistema Armonizado (Harmonized Commodity Description and Coding System, en adelante, HS) desarrollado por la Organización Mundial de Aduanas (OMA/WCO) para clasificar todos los productos y mercancías en el comercio internacional. De este modo, se asegura un cumplimiento indirecto de los criterios de movilidad, alto valor e identificabilidad de los equipos, se parte de la relevancia real de los bienes seleccionados en las operaciones internacionales de financiación en las diversas industrias, y se evitan criterios subjetivos o inciertos como el destino previsto o actual de los bienes o su uso, efectivo o potencial, en la minería, la agricultura y la construcción.

29. El segundo de los desafíos que la extensión del sistema de Ciudad del Cabo a los sectores minero, agrícola y de construcción planteó desde el inicio del proceso de concepción y elaboración del Protocolo MAC derivaba de la posible, y mucho más extendida, intensa y frecuente que en los sectores previamente abordados (aéreo, ferroviario, espacial), conexión, fijación, incorporación o, de cualquier otro modo, asociación de los bienes de equipo (minero, agrícola o de construcción) con bienes inmuebles. Más allá de constatar esta asociación puramente fáctica, la dificultad naturalmente deriva de las implicaciones que esta conexión, física o funcional, permanente o temporal, puede tener, de acuerdo con el dispar tratamiento de las legislaciones nacionales, tanto en la calificación misma del equipo como bien mueble, como en la existencia o la prioridad de la garantía constituida sobre el bien al incorporarse a la propiedad inmueble. Por ello, el Protocolo de Pretoria ha tenido que abordar una cuestión nueva, inexistente porque carecería de relevancia empírica en los Protocolos previos, pero que ha requerido atención y soluciones propias e innovadoras con la expansión del sistema de Ciudad del Cabo a los sectores minero, agrícola y de construcción. Así, el Artículo VII del Protocolo de Pretoria representa, bajo un formato opcional con tres alternativas de declaración obligatoria por los Estados, la respuesta del instrumento internacional a esta compleja situación jurídica derivada de la asociación de un equipo minero, agrícola o de construcción con un bien inmueble (infra $\mathrm{V}$ ).

30. El tercero de los retos a los que la elaboración del Protocolo de Pretoria tuvo que enfrentarse constituye también una desviación de los Protocolos previos. La diferente naturaleza de los bienes, no solo por su uso industrial más habitual, también significa diversas prácticas de financiación y diferentes situaciones transaccionales que pueden requerir soluciones propias e innovadoras. A diferencia de los bienes de equipo aeronáutico, espacial y ferroviario, los bienes mineros, agrícolas y de construcción pueden, con mucha más frecuencia, financiarse como parte del inventario de un distribuidor, concesionario o intermediario que ofrece al público el alquiler, la adquisición u otras formas de uso de los bienes en el ejercicio normal de su actividad. De esta constatación práctica de la industria, derivó de inmediato una doble problemática que fue objeto de amplio e intenso debate hasta la decisión finalmente adoptada en la Conferencia Diplomática.

31. De un lado, la habitual financiación global de un inventario casa con dificultad con la lógica del sistema de Ciudad del Cabo que requiere la identificación única del bien, su inscripción en el Registro 
internacional, con un formato de folio real, y, por tanto, la modificación continua del registro conforme a la rotación del inventario en el curso normal del negocio del intermediario. De otro lado, la adquisición o el alquiler del bien por parte del tercero a través de un intermediario (comercio abierto al público) unido a la posible presencia en estas industrias de operadores adquirentes menos sofisticados que el sector aeronáutico, en el espacial o en el ferroviario. Por este motivo, algunas delegaciones plantearon la consistencia entre las reglas de prioridad que vertebran el sistema de Ciudad del Cabo con una eventual necesidad de protección de la posición de estos terceros adquirentes o arrendatarios de bienes distribuidos o puestos a disposición por un distribuidor o intermediario al público en el curso normal de su actividad empresarial.

32. El tratamiento de estas cuestiones fue compleja y se discutió con intensidad durante las sesiones del Comité de Expertos Gubernamentales y nuevamente durante la Conferencia Diplomática con varias opciones bajo consideración de las delegaciones. El proceso de deliberación de las alternativas posibles y la decisión final que se decantó tras las negociaciones son un ilustrativo reflejo del complejo esfuerzo por mantener la lógica del sistema de Ciudad el Cabo ante escenarios transaccionales propios de los sectores cubiertos por el nuevo Protocolo de Pretoria. El Artículo XII en su versión definitiva condensa el acuerdo final para alcanzar este buscado equilibrio (infra $\mathrm{V}$ ).

33. Estos son los ejes sobre los que de forma más clara y evidente el Protocolo de Pretoria se tiene que desviar del sólido edificio conceptual y de principios que asienta el sistema de Ciudad del Cabo y proyecta sobre los tres Protocolos previos ${ }^{34}$. Hay otros ajustes interesantes, de corte formal pero también sustancial, que se llevan a cabo en el Protocolo de Pretoria para asegurar su acomodación a las prácticas de financiación en la industria, las características de los bienes y la estructura del mercado en los tres sectores objeto de atención. Con las innovaciones más visibles y otros ajustes menos perceptibles, pero de indudable interés, el nuevo Protocolo se integra con éxito en el cuerpo de normas del sistema de Ciudad del Cabo respetando el resto de disposiciones y alineándose plenamente con sus conceptos clave y sus principios fundamentales (infra IV).

\section{El ámbito de aplicación del Protocolo de Pretoria}

34. El ámbito de aplicación del Protocolo de Pretoria viene determinado, primero, por las reglas generales del Convenio que fijan los factores de conexión y describen los criterios generales de aplicación para todas las categorías de objetos y, segundo, por los criterios específicos de definición del objeto para cada categoría de elementos de equipo establecidos en el correspondiente Protocolo. Las particularidades de cada sector han requerido la implementación de fórmulas diversas de delimitación del ámbito objetivo y de descripción de los objetos a los que se aplica el régimen uniforme. El Protocolo de Pretoria ha adoptado un fórmula especialmente novedosa y singular ante las dificultades de describir los bienes de equipo en estos sectores con otras fórmulas que garantizaran el cumplimiento de los criterios de movilidad, alto valor e identificación única.

35. De conformidad con el Convenio (Artículo 2), el Protocolo de Pretoria se aplica a las garantías internacionales constituidas sobre alguna de las categorías de bienes definidas en el Protocolo en virtud de un contrato de garantía, un contrato de arrendamiento (leasing) o un contrato de compraventa con reserva de dominio, si el deudor está situado en un Estado Contratante (Artículo 3). Por tanto, la aplicación del Protocolo pivota sobre la situación del deudor, siendo irrelevante la localización del bien gravado (infra 2), el tipo de acuerdo constitutivo de la garantía internacional y la pertenencia del bien a alguna de las categorías de los bienes sujetos al régimen uniforme (infra 3 y 4). No hay referencia alguna a un criterio de internacionalidad expreso ni independiente como factor de aplicación (infra 1).

${ }^{34}$ B. Von Bodungen; O. Böger, "The Draft MAC Protocol to the UNIDROIT Cape Town Convention on International Interests in Mobile Equipment: A New International Regime for Security Interests in Mining, Agricultural and Construction (MAC) Equipment”, Uniform Commercial Code Law Journal, vol. 45, 2019, pp. 45-122. 
36. Desde el punto de vista del ámbito de aplicación temporal, el Convenio no se aplica a los derechos y garantías preexistentes, conservando la prioridad que tuvieran según la ley aplicable, constituidos con anterioridad a la fecha en que tenga efecto el Convenio que es la fecha más tardía de entre las dos siguientes: la entrada en vigor del Convenio y la incorporación como Estado Contratante del Estado donde el deudor esté situado. Sin embargo, en este punto, el Convenio articula una solución de Derecho transitorio sujeta a la declaración de los Estados Contratantes. De acuerdo con el Artículo 60, mediante la oportuna declaración, un Estado Contratante puede fijar una fecha (tras el transcurso de al menos 3 años desde que tenga efecto la declaración) a partir de la cual, a los efectos exclusivamente de prioridad, el Convenio y el Protocolo resulten aplicables a los derechos y garantías preexistentes. Lo anterior se producirá en la medida y en la forma especificadas en la declaración y sólo en relación con los derechos y garantías preexistentes nacidas de un contrato celebrado por el deudor mientras que éste estuviera situado en el Estado que formula la declaración. Por tanto, el titular de un derecho previo a la fecha en que tenga efecto el Convenio cubierto por tal declaración, dispondrá de un plazo de al menos tres años para inscribir su derecho en el Registro Internacional ganando así prioridad sobre los derechos o garantías ulteriores, si bien convendría que la declaración previera que, en relación con los derechos e intereses previos, mantendrá su prioridad pre-Convenio ${ }^{35}$. El recurso a esta declaración por los Estados Contratantes ha sido limitadísimo y muy infrecuente, prácticamente anecdótico ${ }^{36}$.

\section{El criterio de internacionalidad y las transacciones internas}

37. La postura adoptada en el sistema de Ciudad del Cabo para abordar la cuestión de la internacionalidad se articula con una solución original y pragmática que se encuentra, de hecho, en el origen de la necesidad de establecer un marco uniforme para los elementos de equipo móvil. Así, a diferencia de otros instrumentos internacionales, el Convenio no trata el carácter internacional de forma separada ni expresa, sino que lo presume inherente a la movilidad, real o potencial, de los objetos a los que se aplica. Esta aproximación a la internacionalidad ataca directamente la raíz de la dificultad regulatoria de las operaciones de financiación garantizada sobre elementos naturalmente móviles, con respecto a los cuales la lex res sitae resulta inadecuada o inoperante.

38. El efecto derivado de esta decisión de política legislativa es que el Convenio se aplica tanto a operaciones internacionales como a transacciones puramente internas, en las que todas las partes y el objeto afectado estén situados en el mismo Estado Contratante en el momento de conclusión del acuerdo. El objeto puede variar su localización posteriormente, dotando a la operación de carácter transfronterizo, o permanecer en el Estado originario, manteniendo su ámbito nacional, y, en todo caso, puede hacerlo sin conocimiento del acreedor. $\mathrm{O}$ incluso, una transacción internacional puede derivar de una transacción previa originalmente interna (un sub-leasing que provenga de una operación previa de leasing nacional) ${ }^{37}$. Todas estas vicisitudes resultan, en el esquema original del Convenio, irrelevantes, de modo que el instrumento internacional se aplica en todo caso por razón del objeto y el acuerdo de garantía.

39. No obstante, para atender la oposición de algunos Estados expresada durante las negociaciones a renunciar totalmente a la aplicación del Derecho interno a operaciones puramente nacionales,

${ }^{35}$ La cesión de un derecho preexistente o la adquisición por subrogación tras la fecha en la que tenga efecto el Convenio no afecta a su tratamiento como derecho preexistente, pues no crean una nueva garantía internacional, sino que tan sólo transfieren el derecho preexistente manteniendo la fecha de constitución del mismo. Si quedan cubiertos por la declaración, se aplicarán entonces los efectos descritos que, insistimos, afectan sólo a la prioridad y no suponen la aplicación de otras disposiciones del Convenio. Si las partes, por el contrario, decidieran reemplazar el acuerdo pre-Convenio por uno nuevo, concluido tras la entrada en vigor del Convenio, o incluso recurrieran a la novación del contrato previo, nace entonces una garantía internacional que se rige por el Convenio en todas sus disposiciones, pero el acreedor pierde su prioridad pre-Convenio con respecto a los derechos y garantías anteriores.

${ }^{36}$ Con fecha 4 de septiembre de 2020, únicamente 3 Estados de los 81 Estados Contratantes en esta fecha han realizado una declaración conforme al Artículo 60 (Canadá, Ghana y Méjico).

${ }^{37}$ R. Goode, Official Commentary, third edition, op.cit., p. 145 y par. 4.318, p. 397. 
se ha arbitrado en el Convenio una solución de compromiso en el catálogo de declaraciones. Así, un Estado podrá emitir una declaración, en el momento mismo de ratificación, aceptación, adhesión o aprobación (Artículo 50 del Convenio) al Protocolo o en un momento cualquiera posterior (Artículo 57 del Convenio), por la que el Convenio no se aplique a una transacción que es una transacción interna con respecto a ese Estado y en relación con todos los tipos de objetos o algunos de ellos. Esta declaración de inaplicación no tiene, sin embargo, más que un efecto limitado. De un lado, porque si bien una garantía nacional no puede ser a todos los efectos una garantía internacional, le resultan, en todo caso, de aplicación los Artículos 8 (4), 9 (1), 16, 29 y todas las provisiones aplicables a garantías o derechos inscritos (Capítulo V, en particular, y además Artículos 30, 35 (1) o 40 del Convenio). De otro lado, porque sólo si la garantía creada o provista por una transacción interna - tal y como es definida en el Artículo 1 (n) del Convenio - está además inscrita en un registro nacional ${ }^{38}$ - definición de garantía nacional según el Artículo 1 (r) del Convenio -, resulta efectiva la declaración, para no distorsionar la estructura registral y de prioridad del Convenio. En efecto, las garantías nacionales pueden protegerse, resultándoles de aplicación las reglas de prioridad del Convenio como si de garantías internacionales se tratara, mediante la inscripción de un aviso de garantía nacional (Artículo 1 (t) del Convenio) en el Registro Internacional.

40. Por tanto, una "garantía nacional" requiere la concurrencia de tres requisitos: que en el momento en que se celebra el contrato todos los intereses de las partes y el objeto estén localizados en un mismo Estado; que la garantía se haya inscrito en un registro nacional de ese mismo Estado; y que tal Estado haya emitido oportunamente la declaración al respecto del Artículo $50^{39}$. Si no se satisface alguno de estos elementos, el Convenio resultará aplicable íntegramente a la transacción y a la garantía por ella creada o provista ${ }^{40}$.

41. El requisito cuya determinación resulta más compleja y delicada es, sin duda, el de la localización del objeto. El Convenio ya había logrado eludir esta cuestión con su original fórmula de internacionalidad y, de hecho, en este punto remite a los Protocolos la determinación de los criterios para establecer la situación del objeto en un Estado a los efectos de calificar la transacción como puramente interna.

42. En lo que se refiere a los objetos aeronáuticos, el Artículo IV (2) establece los factores específicos de conexión a los efectos de la calificación de una "transacción interna". Dada la variedad de objetos aeronáuticos cubiertos por el Protocolo y su diverso tratamiento registral en las jurisdicciones nacionales, se prevén tres criterios especiales de localización: el Estado de matrícula de la aeronave de la cual es parte para determinar la localización de una célula de aeronave o de un motor de aeronave instalado, pues ambos objetos carecen de matrícula propia y separada; el lugar donde está físicamente situado para determinar la ubicación de un motor de aeronave no instalado y, por tanto, al que no podemos aplicar el criterio anterior; el Estado de su matrícula para situar un helicóptero, pues es objeto de matriculación propia.

43. El Protocolo Ferroviario diseña una fórmula específica y adaptada a las particularidades del material rodante para determinar el criterio de localización que define las transacciones internas. Así, de conformidad con el Artículo XXIX. $2^{41}$, a los efectos de una declaración bajo el Artículo 50 del Convenio

${ }^{38}$ La rigurosidad interpretativa de este requisito de la inscripción previa es tal que resulta indiferente que la falta de inscripción se deba al hecho de que la garantía en cuestión no es inscribible bajo el Derecho nacional aplicable, el Estado Contratante carezca incluso de registro o la persona legitimada no haya efectuado simplemente la inscripción.

${ }^{39}$ Como referencia, de los 81 Estados Contratantes (más una Organización Regional de Integración Económica) en la fecha de la última consulta tan sólo 5 Estados habían depositado una declaración de acuerdo con el Artículo 50 del Convenio (China, Méjico, Panamá, Turquía y Ucrania). Disponible toda la información actualizada en http://www.unidroit.org/status2001 capetown (última consulta 4/9/2020).

${ }^{40}$ R. Goode, Official Commentary, third edition, op.cit., pars. 2.246-2.247, pp. 145-146.

${ }^{41}$ Artículo XXIX.2 Protocolo Ferroviario:

"For the purposes of Article 50(1) of the Convention, an "internal transaction" shall also mean, in relation to railway rolling stock, a transaction of a type listed in Article 2(2)(a) to (c) of the Convention where the relevant railway rolling stock is only capable, in its normal course of use, of being operated on a single railway system within the Contracting State concerned, because of track gauge or other elements of the design of such railway rolling stock." 
habrá de entenderse como transacción interna aquella relativa a un objeto (material rodante ferroviario) que, en su uso normal, sólo pueda operar sobre un sistema ferroviario específico en el Estado que realiza la declaración por razón del ancho de vía u otros elementos de diseño del equipo.

44. En el caso de los bienes de equipo espacial, la determinación de los criterios para considerar que un bien de equipo espacial está situado en un Estado resulta especialmente compleja y ha de tener en cuenta dos consideraciones particulares. De un lado, el hecho de que los bienes de equipo espacial pueden encontrarse en diversas fases operativas y de explotación, desde la fase terrestre y pre-lanzamiento a la orbitral. Mientras que cuando el dispositivo se encuentra en tierra, no hay problema alguno para determinar su situación física, en el resto de fases de lanzamiento y puesta en órbita es preciso articular criterios específicos. De otro lado, la consideración de que el caso de los satélites y otros dispositivos espaciales no se produce, en realidad, un efecto transfronterizo sino un auténtico efecto de a-nacionalidad o a-territorialidad. El Protocolo opta por el criterio del registro para determinar la situación del bien de equipo espacial para los fines de calificar la transacción como nacional o puramente interna. De modo que, según el Artículo I.3 se entenderá localizado en el Estado Contratante que registra el bien de equipo espacial, o en cuyo registro el bien es inscrito, como "objeto espacial" a los fines de algunos de los instrumentos internacionales de Derecho Espacial ${ }^{42}$.

45. En el Protocolo de Pretoria no se contiene una regla específica para determinar la localización del objeto a los efectos de la calificación de una transacción como transacción interna. Considerando las categorías de bienes cubiertos por este cuarto Protocolo, la determinación de la situación del objeto no plantea dificultades especiales ni requiere un tratamiento diferente al del motor no instalado, bajo el Protocolo Aeronáutico. Por tanto, será la ubicación física del equipo la que determine su localización. De hecho, como luego se verá, se han hecho todos los esfuerzos por evitar que la situación de los bienes sea tratada como factor de conexión relevante en el Protocolo de Pretoria. Esta posibilidad había reaparecido en el proceso legislativo con ocasión de la redacción de las disposiciones aplicables a la financiación de inventario. Se valoraba la conveniencia de que fuera la ubicación del inventario el criterio relevante para la aplicación de la declaración de un Estado Contratante que excluyera las reglas del Protocolo. Así, tras un interesante e intenso debate en la Conferencia Diplomática, se eludió la situación del inventario y se acordó el uso del criterio general de conexión del Convenio que es el domicilio del deudor.

\section{El domicilio del deudor y la irrelevancia de la situación del bien}

46. El Convenio suple la determinación de criterios de internacionalidad con la asunción de una naturaleza inherentemente móvil de los objetos. De esta movilidad, efectiva, potencial, o simplemente asumida, de los objetos resulta la consecuente inadecuación de la lex res sitae $e^{43}$ como regla de conflicto. Por tanto, el Convenio adopta como factor de conexión general la situación del deudor en un Estado Contratante en el momento de la celebración del contrato ${ }^{44}$.

${ }^{42}$ En particular:

“i) el Tratado sobre los principios que deben regir las actividades de los Estados en la exploración y utilización del espacio ultraterrestre, incluso la Luna y otros cuerpos celestes, firmado en Londres, Moscú y Washington D.C. el 27 de febrero de 1967

ii) el Convenio sobre el registro de objetos lanzados al espacio ultraterrestre, firmado en Nueva York el 14 de enero de $1975 ; 0$

iii) la Resolución 1721 (XVI) B de la Asamblea General de las Naciones Unidas de 20 de diciembre de 1961”.

${ }^{43}$ Cuando la naturaleza de los bienes es tendencialmente móvil, "it is no solution to say that the lex situs governs: we require to know which lex situs to apply" - J.H.C. Morris, "The Transfer of Chattels in the Conflict of Law", 22 British Yearbook of International Law, 1945, pp. 232-248, cita en p. 233 -. Los resultados de esta "movilidad" reguladora no son en absoluto satisfactorios, T.J.R. Schilling, "Some European decisions on non-possessory security rights in Private International Law", International and Comparative Law Quarterly, num. 34, 1985, pp. 87-114.

${ }^{44}$ La situación del deudor es el factor general y común de conexión para todos los Protocolos. No obstante, el Protocolo Aeronáutico añade un factor de conexión adicional para ampliar la esfera de aplicación del Convenio en relación con los ob- 
47. El domicilio o la situación del acreedor, la situación del objeto, u otras circunstancias de la transacción son irrelevantes para la determinación de la aplicación del Convenio si el deudor está situado en un Estado Contratante en el momento de la celebración del contrato. Por lo que también sería irrelevante para la aplicación del Convenio si la situación del deudor variara en un momento ulterior o fuera diferente en un momento previo a la celebración del contrato de garantía. A los efectos de determinar el lugar en el que está situado el deudor, el Artículo 4 del Convenio ofrece cuatro alternativas: la ley bajo la que se haya constituido o formado, el lugar de su sede social o estatutaria, el lugar donde tenga su administración central o el lugar en el que esté situado su establecimiento comercial principal, si tiene varios, o, en su defecto, su residencia habitual. Si conforme a cualquiera de estos criterios, se considera que el deudor está situado en un Estado Contratante, se aplica el Convenio con respecto a la categoría de bienes que corresponda.

48. Salvo los casos previamente referidos en el que la situación del bien es pertinente para determinar la concurrencia de los requisitos que permiten calificar una transacción como puramente interna, el criterio de la localización del objeto trata de evitarse en todo lo posible porque, de algún modo, contradice de lleno la filosofía del sistema de Ciudad del Cabo de superación de la lex res sitae como inadecuada e impracticable ante bienes de equipo naturalmente móviles.

49. No obstante lo anterior, la situación del objeto es también relevante para la aplicación de un reducido número de disposiciones del Convenio y el Protocolo correspondiente. En algunos supuestos, los textos uniformes se remiten a la jurisdicción nacional competente y para determinarla se recurre al criterio de la ubicación del objeto. En particular, en lo que se refiere a los bienes de equipo espacial, la aplicación del Artículo 43.1 del Convenio, sobre adopción de medidas provisionales ${ }^{45}$, y del Artículo XXII del Protocolo, sobre asistencia entre jurisdicciones en casos de insolvencia, dependen del Estado contratante donde se encuentre localizado el bien. Cuando el dispositivo no está en tierra, se considerará que este Estado Contratante es alguno de los siguientes: el Estado Contratante que haya registrado el objeto espacial (según nos hemos referido anteriormente conforme al Artículo I.3); el Estado Contratante que haya emitido la licencia que permite operar el bien de equipo espacial; o el Estado Contratante en el que se encuentre el centro de la misión de control de tal dispositivo. No hay en el Protocolo ni una regla de prioridad entre las jurisdicciones potencialmente competentes ni criterios para resolver un posible conflicto.

50. El Protocolo de Pretoria ofrece también otro interesante caso en el que la situación del objeto es relevante para la determinación de la ley aplicable. El Artículo VII, desde la versión del instrumento discutida en la primera sesión del Comité de Expertos Gubernamentales ${ }^{46}$, regula los efectos de la aso-

jetos aeronáuticos (Art. II (2) del Protocolo). Sin perjuicio de los casos en los que resulte de aplicación el Convenio en virtud de la situación del deudor, además se aplicará en relación con un helicóptero o con una célula de aeronave perteneciente a una aeronave, inscritos en el registro de aeronaves de un Estado, denominado el Estado de matrícula, que sea un Estado Contratante. Es un criterio adicional y alternativo, pero no un requisito necesario y cumulativo en el caso de objetos aeronáuticos, es decir, si el deudor está situado en un Estado Contratante, no es relevante que el Estado de Registro no sea un Estado Contratante (y a la inversa) - M. Deschamps, Michel, "Les règles de priorité de la Convention et du Protocole du Cap", Rev.Dr.Unif./ Unif.L.Rev., 2002-1, pp. 17-48, en p. 20 -. Naturalmente este factor de conexión alternativo (Estado de matrícula) no resulta aplicable a los motores de aeronaves pues estos no son susceptibles de inscripción o matrícula en los referidos Registros. Por tanto, puesto que la ubicación real del motor es irrelevante, la regla general de la situación del deudor en un Estado contratante será la que única que pueda determinar la aplicación del Convenio en conjunción con el Protocolo Aeronáutico

${ }^{45}$ Artículo 43.1 del Convenio:

"Los tribunales de un Estado contratante elegidos por las partes y los tribunales del Estado contratante en cuyo territorio está situado el objeto tienen jurisdicción para ordenar medidas en virtud de los apartados a), b) y c) del párrafo 1 del Artículo 13 y del párrafo 4 del Artículo 13 respecto a dicho objeto."

Las medidas del Artículo 13 a las que se refiere esta disposición son:

a) la conservación del objeto y su valor;

b) la posesión, el control o la custodia del objeto;

c) la inmovilización del objeto;

y cualquier otra medida provisional que pueda ser ordenada, aplicándose todas ellas de manera comercialmente razonable (Artículo 8.3 del Convenio).

${ }^{46}$ Study 72K - CGE1 - Doc. 2 corr., disponibles en http://www.unidroit.org/english/documents/2017/study72k/cge01/s-72kcge01-02corr-e.pdf. 
ciación de un objeto (bien de equipo agrícola, minero o de construcción) con un inmueble por razón de su instalación, incorporación, uso, función o destino -. El tratamiento de estas situaciones de asociación o relación estrecha, física o funcional, entre el bien mueble y el bien inmueble, en las diversas jurisdicciones es notablemente dispar tanto en los criterios para su calificación, como en las consecuencias jurídicas ${ }^{47}$. Por ello, el Study Group propuso que el Artículo VII se articulara como una disposición alternativa que contemplara tres diversas soluciones para que los Estados optaran mediante una declaración en el momento de ratificación, adhesión, aceptación o aprobación del Protocolo. Tanto la aplicación de la declaración efectuada por cada Estado como las consecuencias previstas bajo cada uno de las alternativas que la disposición ofrece tienen como punto de conexión la situación el objeto que ha devenido un bien de equipo asociado a un inmueble y que es, naturalmente, la ubicación del bien inmueble.

51. Precisamente esta política de elusión del criterio de localización del bien como factor relevante en el sistema de Ciudad del Cabo permitió resolver un largo debate, ya referido, que se extendió incluso durante las sesiones de la Conferencia Diplomática, sobre cuál debía ser el factor de conexión para la aplicación del régimen opcional sobre la financiación de inventario. Se discutió la conveniencia de recurrir al lugar en el que se encuentra el inventario para determinar la aplicación del Artículo XII y la declaración, en su caso, del Estado Contratante en este sentido. Si bien volveremos más adelante (infra V) y con más profundidad a esta disposición, interesa aquí avanzar el debate abierto sobre si el factor de conexión para la aplicación de la declaración de exclusión de un Estado debía ser la ubicación del inventario (lex res sitae) o la situación del deudor. Primó la insistencia en la necesidad de mantener un factor de conexión consistente con el sistema de Ciudad del Cabo que se fundamenta en la situación del deudor, pues, de hecho, es una respuesta ante la inoperancia de la res sitae en equipos móviles. La ubicación del inventario es además un criterio que puede ser cambiante, difícil de determinar (en tránsito), ajeno totalmente a los elementos de la transacción, o inconsistente con las modernas prácticas comerciales (centros logísticos o de almacenaje en país tercero). Por ello, se acordó finalmente, el empleo de la situación del deudor como criterio único. De entre los criterios del Artículo 4 del Convenio, se optó por elegir únicamente uno de ellos: el establecimiento principal del deudor.

\section{La singular fórmula de delimitación del ámbito de aplicación objetivo en el Protocolo de Preto- ria: los bienes mineros, agrícolas y de construcción}

52. La elaboración de un cuarto Protocolo que extendería el Convenio de Ciudad del Cabo, bajo la habilitación del Artículo 51, a categorías de nuevos elementos de equipo móvil no previstos inicialmente en el Artículo 2.3 del Convenio, ha tenido que enfrentarse desde el momento inicial a las dificultades que la delimitación del ámbito de aplicación planteaba en estos sectores. A lo largo del todo el proceso de redacción y negociación, surgieron sistemáticamente dudas ${ }^{48}$ sobre cómo identificar en los sectores de la minería, la agricultura y la construcción aquellos equipos que responden a los criterios de delimitación material que vertebran el sistema de Ciudad del Cabo. Además, también se debía valorar la idoneidad de la opción de elaborar un único Protocolo que cubriera tres sectores y cómo articular la adhesión de los Estados aun instrumento multisectorial.

53. El Protocolo MAC resulta un componente particularmente singular y complejo en el sistema de Ciudad del Cabo y ofrece interesantes e innovadoras soluciones para resolver la delicada cuestión del

\footnotetext{
${ }^{47}$ Sobre esta cuestión y el impacto creciente en la armonización de las normas sobre garantías mobiliarias, T. RODRÍGUEZ DE Las Heras Ballell, "Right of Accession, Ownership of Property, and Extension of Security Interests: Concepts, Conflicts, and Rules", Philippines Journal of Legal Education, vol. III, 2016, pp. 1-30. El trabajo concluye que la cada vez más visible colisión entre derechos de garantía sobre bienes muebles, sujetos a reglas uniformes, y la dispar regulación de las garantías sobre bienes inmuebles pone de manifiesto la necesidad de plantear iniciativas para el progresivo acercamiento de las normas nacionales sobre garantías sobre inmuebles.

${ }^{48}$ UNIDROIT 2006 - C.D. (85) 19, p. 10; UNIDROIT 2009 - C.D. (88) 17, pars. 143 - 147; UNIDROIT 2010 - C.D. (89) 17; pars 33 - 3.7; UNIDROIT 2011 - C.D. (90) 18, pars. 68 - 70; UNIDROIT 2012 - C.D. (91) 15, pars 46 - 47; UNIDROIT 2013 - C.D. (92) 17, pars. 44 - 48; UNIDROIT 2014 - C.D. (93) 14, pars. 34 - 38.
} 
ámbito de aplicación tanto en su perspectiva externa - la extensión a tres sectores -, como en su perspectiva interna - la elección de factores adecuados para la delimitación material de la esfera de aplicación $-{ }^{49}$.

\section{A) La decisión de adoptar un único Protocolo para tres sectores}

54. La decisión de elaborar un Protocolo conjunto para los tres sectores debía tener en cuenta ciertas consideraciones. De un lado, de tipo técnico, la conveniencia de tratar en el mismo instrumento tres sectores tan diferentes y la viabilidad de un texto único capaz de coordinar eficazmente reglas adecuadas para cada categoría de objetos. De otro lado, de corte político, los diversos intereses que los Estados podrían tener en relación con cada uno de los sectores según el modelo económico, los colectivos afectados, o razones estratégicas o sociales ${ }^{50}$.

55. Para atender estas consideraciones y lograr así el máximo consenso entre los Estados, se implementa la decisión unitaria, pero con una fórmula de flexibilidad. El Protocolo cubre de forma unitaria y conjunta los tres sectores, pero los Estados podrán en el momento de acceso, aprobación, adhesión o ratificación optar por su aplicación a la totalidad o parcialmente a una o dos de las categorías de bienes y seleccionar cuáles (Art. II.3). De igual modo, en un momento ulterior, un Estado Contratante podrá denunciar la aplicación del Protocolo, no sólo en su integridad, sino sólo con respecto a una o dos de las categorías cubiertas y previamente aceptadas en la ratificación (Art. XXXI). Esta flexibilidad, sin embargo, no penetra en todo el articulado del texto, pues las declaraciones que los Estados realicen de conformidad con el Convenio y el Protocolo (Art. XXVI) se aplicarán a todos los equipos a los que, en cada Estado, el Protocolo resulte de aplicación. Es decir, en los casos en los que el texto permite a los Estados realizar una declaración para la aplicación o exclusión de una disposición (opt-in u opt-out) o elegir entre las alternativas que los Artículos VII y X ofrecen, tal decisión no podrá ser diferente para las diversas categorías de bienes $^{51}$. Como se explica a continuación, dada la peculiar fórmula elegida para delimitar el ámbito de aplicación, permitir a los Estados la realización de diferentes declaraciones o alternativas según la categoría de bienes no es adecuado porque genera dificultades en la aplicación y provoca el solapamiento entre las diversas categorías. Con similar razonamiento, aunque se consideró inicialmente por el Study Group esta posibilidad, se opta por no contemplar una entrada en vigor diferenciada para cada uno de los Anexos por la complejidad que esta fórmula entrañaría. Una vez que el Protocolo de Pretoria entra en vigor, lo hace con respecto a los tres sectores y en relación con las categorías de bienes contemplados en los tres Anexos, sin distinguir, en su caso, si los Estados Contratantes han ratificado todos los Anexos o sólo uno o dos de ellos.

56. Confirmada la decisión de mantener un Protocolo único para los tres sectores, una de las tareas más complejas que la elaboración del instrumento ha debido resolver es el diseño de una fórmula adecuada para delimitar el ámbito de aplicación.

\section{B) El recurso al Sistema Armonizado de la Organización Mundial de Aduanas para la delimita- ción de las categorías de bienes}

57. En la delimitación del ámbito de aplicación era preciso conciliar dos intereses que pueden actuar en la práctica en sentido contrario. De un lado, la necesidad de mantener la lógica del sistema de

${ }^{49}$ C.W. Mooney; M. Dubovec; W. Brydie-Watson, "The Mining, Agricultural and Construction Equipment Protocol to the Cape Town Convention Project: The Current Status”, Unif. L. Rev., num. 21(2-3), 2016, pp. 332-360.

${ }^{50}$ La consulta realizada a los Estados en 2008 recogió opiniones diversas y contrarias sobre la conveniencia de separar el proyecto unitario en tres Protocolos diferentes. Si bien algunos Estados se inclinaban por la separabilidad, otros muchos consideraban que razones de economía, eficiencia y agilidad aconsejaban mantener el enfoque unitario. UNIDROIT 2014 - Study $72 \mathrm{~K}$ - SG1 - DOC. 2, p. 7.

${ }^{51}$ UNIDROIT, 2017 - Study 72K - CGE1 - Report, par. 69, p. 8, disponible en http://www.unidroit.org/english/documents/2017/study72k/cge01/s-72k-cge01-report-e.pdf. 
Ciudad del Cabo como un instrumento aplicable a ciertas categorías específicas de bienes que satisfacen los criterios de alto valor, identificación única, y movilidad. De otro lado, la aspiración de asegurar el máximo beneficio económico para los Estados que decidan ratificar el Protocolo con una aplicación lo más amplia y comprensiva posible.

58. El punto de partida lógico para emprender esta tarea era tomar los tres criterios con los que el Artículo 51 del Convenio delimita objetivamente el área de expansión del sistema uniforme y definirlos de forma específica para los sectores implicados. Sin embargo, este enfoque pronto se muestra extremamente complejo, incierto y poco consistente en la práctica. La amplia diversidad de equipos empleados en la actividad agrícola, minera y de construcción y la disparidad en la praxis de la financiación sectorial dificultaban todo esfuerzo por configurar una solución basada en la aplicación de los criterios materiales del Artículo 51. Si bien en el sector aeronáutico, la propia selección de los objetos - células de aeronaves, motores y helicópteros - implicaba de forma natural limitar la aplicación a equipos de alto valor sin necesidad de fijar adicionalmente un umbral cuantitativo, el rango de oscilación del valor de los objetos empleados en explotaciones agrícolas, mineras o de construcción es inmenso y podría conducir fácilmente a incorporar al Protocolo elementos de mínimo valor o comparativamente muy bajo. Pero la fijación de un límite cuantitativo para definir los equipos de alto valor tampoco es una solución óptima. Asimismo, al igual que en Protocolo Ferroviario, y a diferencia de los Protocolos Espacial y Aeronáutico, la presunción de movilidad innata en los equipos es mucho más débil.

59. Por tanto, era preciso buscar una fórmula que, obviando la definición de los criterios de alto valor, movilidad e identificación única, describa de forma clara y predecible aquellas categorías de objetos que, de hecho, satisfagan tales criterios. Tras valorar y comparar varias alternativas, en la reunión de enero de $2014^{52}$ se propuso el uso del Sistema Armonizado de Descripción y Codificación de Mercancías (Harmonized Commodity Description and Coding System, en adelante, Sistema Armonizado o HS por sus siglas en inglés) desarrollado por la Organización Mundial de Aduanas (OMA/WCO $)^{53}$ para clasificar todos los productos y mercancías en el comercio internacional. El HS proporciona una nomenclatura uniforme para describir, clasificar y codificar mercancías y productos facilitando así el intercambio de información en el comercio internacional. El sistema se utiliza a nivel global ${ }^{54}$ para diferentes finalidades, como la aplicación de las tarifas aduaneras o la recogida de datos para estadísticas comerciales. Según la información proporcionada por la propia $\mathrm{WCO}^{55}$, el $98 \%$ de las mercancías en el comercio internacional está clasificado conforme al HS. Con estas características, el HS ofrecía una herramienta muy útil y eficaz para identificar las categorías de objetos susceptibles de ser incorporados al Protocolo MAC.

60. El Sistema Armonizado clasifica los productos por su composición, su forma o su función mediante dígitos y conforme a una estructura jerárquica que clasifica los códigos en Secciones, Capítulos, Títulos y Subtítulos de forma descendente y en orden de especificidad. La nomenclatura común alcanza hasta los códigos de seis dígitos que se agrupan bajo subtítulos. Adicionalmente, los países individualmente o las organizaciones regionales, como las Unión Europea, pueden añadir sub-secciones con códigos de ocho o incluso diez dígitos. Puesto que esta nomenclatura ya no es uniforme ni armonizada, no resulta pertinente ni adecuada a los efectos de delimitación del ámbito de aplicación del Protocolo. Por

${ }^{52}$ El segundo Issues Dialogue que tuvo lugar en enero de 2014. UNIDROIT 2014 - Study 72K - SG1 - DOC. 2, p. 3.

${ }^{53}$ El HS está regido por la Convención Internacional sobre el Sistema Armonizado de Descripción y Codificación de Mercancías de 14 de junio de 1983, tal y como resultó modificada por el Protocolo de 24 de junio de 1986. Así se define expresamente y a los efectos del Protocolo de Pretoria en el Artículo I(2) letra i).

${ }^{54}$ A fecha 21 de febrero de 2020, el Convenio Internacional que gobierna el Sistema Armonizado cuenta con 158 Estados Parte (más la Unión Europea) y se aplica en 212 países, territorios o uniones económicas o aduaneras en todo el mundo. La lista se detalla en http://www.wcoomd.org/-/media/wco/public/global/pdf/topics/nomenclature/overview/hs-contracting-parties/ list-of-countries/countries_applying_hs.pdf?db=web.

${ }_{55} \mathrm{http} / / /$ www.wcoomd.org/en/topics/nomenclature/overview/what-is-the-harmonized-system.aspx (última consulta $15 / 6 / 2020)$ 
tanto, en el Protocolo de Pretoria sólo se emplean los códigos de seis dígitos. En la versión de 2017, el Sistema Armonizado contenía 96 capítulos que agrupaban en 1.224 títulos, 5.244 códigos de seis dígitos.

61. Con la participación de la industria (representada por el MAC Working Group), se seleccionaron inicialmente aquellos códigos que agrupan objetos que satisfacen los criterios materiales del Artículos 51 y que se financian separadamente en el comercio internacional. Esta primera selección se discutió en las sesiones del CEG y se abrió un periodo para que los Estados pudiera proponer códigos adicionales, de especial interés para su industria, o solicitar motivadamente la exclusión de los inicialmente incluidos. Para tomar en consideración todas las propuestas presentadas por los Estados y adoptar la decisión final, se constituyó en el seno de la Comisión en Pleno de la Conferencia Diplomática el Comité de Códigos del Sistema Armonizado (Harmonized System Committee) para analizar los códigos inicialmente incluidos en los Anexos del borrador de Protocolo, valorar las consideraciones de la Secretaría de UNIDROIT (DCME-MAC - Doc. 6) y analizar las 71 propuestas de adición o exclusión de códigos (42 códigos nuevos) de aquellos Estados que las habían remitido (DCME-MAC - Doc. 3).

62. El análisis de los códigos y la decisión sobre el listado final de los Anexos, como consta en el informe final (DCME-MAC - Doc. 20) del Comité presentado ante la Comisión en pleno el día 16 de noviembre de 2019 y adoptado sin cambios en la misma sesión, estuvieron marcados por la satisfacción de los requisitos y criterios determinantes del ámbito de aplicación material del Protocolo:

- Que los códigos cubrieran equipos de uso predominante en los sectores de minería, agricultura y construcción;

- Que los códigos cubrieran equipo, especialmente, de alto valor;

- Que los códigos se refirieran a equipos completos en vez de a partes o componentes;

- Que los códigos cubrieran equipos utilizados in situ en los sectores minero, agrícola y de construcción y se evitaran equipos multifuncionales que carezcan de conexión directa y previsible con algunos de los sectores objeto del Protocolo ${ }^{56}$.

Bajo estos criterios, el Comité propuso los cambios correspondientes en los Anexos que fueron confirmados por el Pleno. De modo que el texto adoptado del Protocolo incluye 56 códigos de los cuales 25 corresponden al Anexo 1 (minería), 36 al Anexo 2 (agricultura) y 35 al Anexo 3 (construcción).

63. Con esta innovadora solución, el Protocolo MAC define (Art. I.2) (57 $^{57}$ ámbito de aplicación mediante la remisión a los códigos del HS listados en el Anexo correspondiente. De este modo, no se ha de realizar un test previo ni ulterior para verificar el cumplimiento de los criterios del Artículo 51 de los bienes identificados en los códigos, ni la finalidad del uso o el uso real o potencial del equipo en alguno de estos sectores es relevante, ni el propósito para el que el equipo ha sido diseñado es un factor de interés. Si el equipo está contenido en los códigos enumerados en el Anexo, y sólo en tal caso, el Protocolo se aplicará. Por ello, si un código aparece incluido en varios anexos porque describe equipos susceptibles de utilización en varios sectores, la finalidad principal o el uso efectivo serán irrelevantes (Artículo II(1)).

64. Si un Estado sólo hubiera ratificado el Protocolo en relación con una de las categorías de objetos, el instrumento se aplicará a todos los objetos cubiertos por los códigos del Anexo que corresponda,

\footnotetext{
${ }^{56}$ Así lo exponen, con algunos ejemplos de códigos que decidieron excluirse por referirse a vehículos para transporte de mercancías en general, M. Dubovec; P.L. Durham, "More Good News From Cape Town: How the New MAC Protocol Will Benefit the Mining, Agriculture and Construction Industries", Journal of Equipment Lease Financing, Volume 35, Number 1, Winter 2017, pp. 1-6, en p. 2.

${ }^{57}$ Artículo I.2.a), b) y h):

“a) "agricultural equipment" means an object that falls under a Harmonised System code listed in Annex 1 to the Protocol (...)

b) "construction equipment" means an object that falls under a Harmonised System code listed in Annex 2 to the Protocol (...) (...)

h) "mining equipment" means an object that falls under a Harmonised System code listed in Annex 3 to the Protocol (...)"
} 
con total independencia del uso efectivo de un concreto equipo en ese u otro sector ${ }^{58}$. Por ejemplo, si un Estado ratificara el Protocolo sólo en relación con el equipo agrícola (Anexo 1), las garantías sobre los objetos cubiertos por el código $842919^{59}$, que está incluido en el Anexo 1 pero también en los Anexos 2 y 3 , quedarán sujetas al Convenio (en relación con el Protocolo), en cualquier caso, sin que tenga relevancia alguna que tales equipos (excavadoras, niveladoras, cargadoras) se empleen efectivamente en una actividad agrícola o estén incorporados, por el contrario, a una explotación minera o de construcción.

65. La función de los códigos del HS incluidos en los Anexos está limitada única y exclusivamente a determinar el perímetro objetivo del Protocolo de Pretoria. Es decir, representa una singular fórmula, importada de un régimen uniforme ajeno (el Sistema Armonizado de la OMA/WCO) concebido con fines diversos, para determinar las categorías de bienes sujetos al sistema de Ciudad del Cabo (Convenio y Protocolo MAC) sin tener que verificar el cumplimiento de los criterios de movilidad, alto valor e identificación única. Esta es la única función de los códigos del Sistema Armonizado y su relevancia finaliza ahí. Por tanto, los códigos del HS no tienen que utilizarse en los acuerdos que las partes concluyan para articular contractualmente las operaciones de financiación, ni operan como instrumento de descripción del bien ni en el contrato ni la inscripción en el Registro Internacional pues, de hecho, el código del HS no es un criterio de identificación del bien para su registro. Más aún, si las partes decidieran referirse en el contrato a los códigos del HS para la identificación del bien gravado, tal mención no sería por sí sola determinante de la aplicación o no del Protocolo. De modo que, si incurrieran en una identificación errónea del código correspondiente, sería irrelevante para la aplicación del Protocolo.

66. Además, conviene añadir otra precisión sobre el alcance de los códigos del Sistema Armonizado como técnica de delimitación del ámbito de aplicación objetivo del Protocolo. El hecho de que el Sistema Armonizado se emplee para, entre otros fines, funciones aduaneras o estadísticas de comercio internacional no implica, en absoluto, que la aplicación del Protocolo de Pretoria requiera necesariamente una operación de exportación/importación del bien objeto de la garantía internacional, ni que la intervención de las autoridades aduaneras sea necesaria en la fase de constitución de la garantía o para la comprobación de que el régimen uniforme es aplicable.

\section{C) La interacción del Protocolo de Pretoria con Protocolos previos}

67. Esta original e innovadora solución técnica, que diseña con maestría la delimitación material del Protocolo y asegura su consistencia interna, plantea, sin embargo, dos delicadas cuestiones asociadas a la interacción del Protocolo con otros instrumentos.

68. De un lado, la relación con otros Protocolos del Convenio de Ciudad del Cabo. Las diferentes técnicas empleadas en los Protocolos para delimitar su ámbito de aplicación pueden producir solapamientos. El amplio criterio operativo del Protocolo Ferroviario (circulación por, sobre o bajo una guía o raíl) absorbería todo vehículo empleado en una explotación minera o en la actividad de construcción cubierto a su vez por códigos incluidos en los Anexos del nuevo Protocolo. Este solapamiento no es admisible en el sistema, no sólo por la incertidumbre sobre las reglas materiales aplicables, sino fundamentalmente por una indeseable duplicación en la inscripción.

69. Esta colisión podía resolverse mediante soluciones ex post de prioridad que asumieran el solapamiento de los ámbitos de aplicación y establecieran un orden de preferencia, o bien mediante una solución ex ante en sede del ámbito de aplicación que previniera y evitara la coincidencia objetiva de los

\footnotetext{
${ }^{58}$ UNIDROIT 2016 - Study 72K - CGE1 - Doc. 4, p. 14.

${ }^{59}$ En la versión del texto publicada como UNIDROIT 2017 - Study 72K - CGE1 - Report - Appendix IV:

"842919: Self-propelled bulldozers, angledozers, graders, levelers, scrapers, mechanical shovels, excavators, shovel loaders, tamping machines and road rollers -- Bulldozers and angledozers - Other”.
} 
instrumentos. Se ha optado por una solución quirúrgica absoluta (Art. II.4) ${ }^{60}$, evitando la coincidencia de ámbitos de aplicación, de modo que no se aplicará el nuevo Protocolo a objetos (aun incluidos en los códigos) que a los efectos de los respectivos Protocolos sean "objetos aeronáuticos", "material rodante ferroviario", o "bienes de equipo espacial".

\section{D) La adaptación del Protocolo de Pretoria a las revisiones del Sistema Armonizado: revisiones, ajustes y modificaciones}

70. De otro lado, la interacción con el Harmonized System de la WCO que le sirve de base. El estudio realizado sobre el funcionamiento y la estructura del HS y presentado al Study Group ${ }^{6 l}$ analiza el proceso de modificación de los códigos por el WCO y valora el impacto que estos posibles cambios nominales, estructurales, o materiales (renumeración, división de códigos, adición de códigos nuevos, eliminación de códigos por obsolescencia, correcciones, supresión de sub-códigos) tienen sobre la estabilidad y la consistencia del sistema de nomenclatura uniforme. La dependencia del Protocolo del HS para la delimitación de su ámbito material requiere implementar un proceso de seguimiento y aceptación de los eventuales cambios futuros. El ámbito de aplicación del Protocolo MAC no queda cristalizado en el momento de su adopción ni siquiera permanecería inalterado para un Estado Contratante desde el momento de adhesión o ratificación.

71. Esta eventualidad despierta delicadas cuestiones sobre la vinculación de los Estados a un Tratado de ámbito mudable y confines inciertos. Así lo plantearon algunas delegaciones ${ }^{62}$ en la primera sesión del CEG celebrada en Roma en marzo de 2017. Dada la seriedad del problema y su afectación directa a las decisiones de política legislativa más distintivas del Protocolo, se constituyó un grupo de trabajo especial (Working Group on Amendments Provisions) ${ }^{63}$ para analizar alternativas y proponer al plenario. El grupo de trabajo logró alcanzar una solución de consenso, consistente en mantener intacta la lógica y la estructura del Protocolo MAC con su base en los códigos HS y su listado en Anexos y trabajar en la implementación de un equilibrado procedimiento de revisión, propuesta, control y aceptación de los cambios por los Estados (Art. XXXII resultante) ${ }^{64}$. La nueva versión del texto del Artículo XXXII fue aprobada en la sesión en pleno por el Comité de Expertos como una solución aceptable y adecuada.

72. Tras la aplicación simulada del Artículo XXXII, tal y como se adoptó en la CEG1, a la revisión de los códigos HS 2012 en 2017, se detectaron algunas debilidades en el modelo y se identificaron resultados poco deseables porque producían fragmentación, incertidumbre en la aplicación del Protocolo, o falta de correspondencia entre los Anexos, si no se modifican, y las versiones actualizadas del HS. Se propuso, por tal motivo, un documento de trabajo por las delegaciones de Japón y España para analizar los diferentes supuestos que podrían generarse y discutir alternativas a la redacción actual ${ }^{65}$. Esta propuesta se discutió en el plenario del CEG1 del viernes 6 de octubre de 2017, decidiéndose que se trabajaría con la Secretaría de UNIDROIT para definir alternativas y proponer una nueva redacción.

\footnotetext{
${ }^{60}$ Artículo II.4 MAC Protocol:

"4. This Protocol does not apply to objects falling within the definition of "aircraft objects" under the Protocol to the Convention on International Interests in Mobile Equipment on Matters Specific to Aircraft Equipment, "railway rolling stock" under the Luxembourg Protocol to the Convention on International Interests in Mobile Equipment on Matters Specific to Railway Rolling Stock or "space assets" under the Protocol to the Convention on International Interests in Mobile Equipment on Matters Specific to Space Assets."

${ }^{61}$ UNIDROIT 2016 - Study 72K - SG4 - DOC. 8, Appendix I.

${ }^{62}$ UNIDROIT 2017 - Study 72K - CGE1 - Report, p. 15.

63 Del que la autora de este trabajo fue nombrada Chair.

${ }^{64}$ UNIDROIT 2017 - Study 72K - CGE1 - Report, pp. 15 y 16, ver párrafos 140 a 148

${ }^{65}$ Un estudio detallado de todo el proceso y de los diversos modelos considerados, en T. RODRÍGUEZ DE LAS HERAs BALLELL; M. HARA, "MAC Protocol and Treaty Design: Examination of the Delimitation of Scope and Mechanism of Amendment", Cape Town Convention Journal, Volume 6, 2017, pp. 10-36.
} 
73. La complejidad de los posibles escenarios que podían afectar al ámbito de aplicación del Protocolo de Pretoria por efecto de las revisiones, modificaciones, ajustes o cambios en la interpretación del HS, unida al delicado equilibrio de intereses que había que lograr entre control de los Estados y flexibilidad del Protocolo, hicieron que la configuración del sistema de adaptación del Protocolo a los cambios del HS se extendiera durante toda la Conferencia Diplomática. Y, de hecho, su redacción final, en gran parte nueva, se concluye por el Comité de Cláusulas Finales durante la Conferencia Diplomática.

74. El Comité de Cláusulas Finales ${ }^{66}$ en la Conferencia Diplomática inicia su trabajo de propuesta, deliberación y redacción a partir de los siguientes objetivos de política legislativa: a). Asegurar que los Anexos del Protocolo se mantuviera alienados con las versiones sucesivas del Sistema Armonizado (HS) que la OMA/WCO iba aprobando, en todo lo posible; b). garantizar que los Estados Contratantes mantuvieran el control sobre los cambios de sus obligaciones internacionales derivadas del Protocolo; c). lograr que el sistema de ajuste del Protocolo sea flexible, ágil y fácil de articular; d). preservar la seguridad jurídica y del tráfico comercial con un sistema previsible y transparente.

75. Conforme a estos objetivos fundamentales, el Comité de Clausulas Finales revisó el texto inicial del Artículo XXXIII, la propuesta de la Secretaría, y las propuestas de algunos Estados. En esta revisión, se detectaron varios elementos que debían atenderse debidamente e incorporarse en el texto:

- Reducir los costes del procedimiento con un sistema en dos pasos: aprobación tácita (no presencial) seguida de una reunión de los Estados únicamente en caso de que falle el procedimiento anterior.

- Facilitar la implementación de los cambios por parte de los Estados Contratantes ofreciendo un mayor tiempo para la implementación de los ajustes en el Derecho interno.

- Establecer un procedimiento flexible para articular cambios en los códigos de los Anexos que no estuvieran relacionados con ni deriven de las revisiones del Sistema Armonizado.

76. Con estos objetivos, la solución que se acuerda en la Conferencia Diplomática se basa en la distinción entre tres situaciones diversas que se sujetan a tres procedimientos diferentes contemplados respectivamente en los Artículos XXXIV, XXXV y XXXVI del texto final:

a) Artículo XXXIV. Toda revisión del texto del Protocolo quedará sujeto al procedimiento general y común a otros Protocolos previsto en el Artículo XXXIV. Consiste en una Conferencia de Revisión de los Estados Parte, convocada por el Depositario, que podrá acordar cambios en el Protocolo con una mayoría de dos tercios de los Estados participantes en la Conferencia. El resto de revisiones del Protocolo quedan sujetas a los procedimientos previstos en los Artículos XXXV y XXXVI.

b) Artículo XXXV. Esta disposición regula el procedimiento aplicable a los cambios (que se denominan "ajustes") en los Anexos, únicamente derivados de una revisión del Sistema Armonizado por parte de la OMA/WCO.

c) Artículo XXXVI. Esta nueva disposición contempla los supuestos denominados de "modificación de los Anexos" que son los cambios que se puedan producir en los códigos de los Anexos que no deriven de la revisión periódica del Sistema Armonizado (HS).

77. Estas disposiciones, largas, detalladas y algo complejas, logran un equilibrio muy razonable entre varios factores que concurren en las diversas situaciones contempladas en los artículos. Era fundamental mantener el Protocolo de Pretoria actualizado con respecto a los cambios en los códigos HS que

${ }^{66}$ La delegación de España fue nominada para formar parte del Final Clauses Committee junto con otras 11 delegaciones designadas y 3 organizaciones internacionales, bajo la presidencia compartida de la delegación de Sudáfrica y la delegación del Reino Unido y la Secretaría de UNIDROIT. El Final Clauses Committee_se reunió después de las sesiones plenarias y produjo su primer informe provisional el 15 de noviembre para su presentación al Pleno. El informe final del comité se completó la segunda semana de sesiones, se presentó al Pleno y quedó adoptado e incorporados sus cambios en el texto final del Protocolo. 
sirven de referencia para la delimitación de su ámbito de aplicación objetivo, pero a la vez abierto y flexible para acomodar las innovaciones en la industria, la modernización de los equipos por efecto de la tecnología y la simple y natural obsolescencia del equipamiento industrial. Era además crítico garantizar un suficiente control de los Estados sobre eventuales alternaciones en la extensión de sus obligaciones internacionales y, por tanto, sobre las revisiones del texto del Protocolo; pero sin crear procedimientos excesivamente largos y onerosos que hicieran la adaptación impracticable o excesivamente complicada. Era, por eso, muy importante evitar que estos procedimientos supusieran una carga innecesaria e ilógica al Depositario con altos costes en la gestión de los instrumentos de adhesión de los Estados y sus declaraciones. Y, finalmente, era esencial preservar la previsibilidad del sistema para las partes contratantes, con altos niveles de seguridad jurídica, certeza y transparencia en la aplicación del texto uniforme a las transacciones internacionales.

\section{4.- EI tratamiento de partes y componentes y el principio de accesión}

78. La lógica, la propia configuración normativa y, en gran medida, el éxito del sistema de Ciudad del Cabo, dependen esencialmente de la decisión de establecer un marco uniforme para los esquemas contractuales con función de garantía sobre objetos perfectamente identificables de forma única que permitiera, de hecho, una inscripción basada en el bien y no en el deudor. Esta decisión de política implica, de un lado, limitar las categorías de bienes a aquellos que dispongan de identificadores únicos y que respondan a una práctica consolidada de financiación separada.

79. Las implicaciones más inmediatas de este enfoque pragmático, constatado con la industria, se proyectan sobre dos áreas. De un lado, la identificación suficiente de los objetos a los efectos de su inscripción en el Registro internacional correspondiente. De otro lado, el tratamiento de las partes, componentes o accesorios instalados, incorporados o de algún modo asociados al bien con respecto a la extensión del derecho de garantía. Esta delimitación del objeto es absolutamente esencial para la coordinación del texto uniforme con otros instrumentos internacionales o con la ley nacional aplicable, para la correcta aplicación de las normas de prioridad, y para la determinación de la preservación de derechos previos en casos de instalación, incorporación o asociación. Por tanto, son precisas reglas de delimitación material del concepto de "objeto" y normas para articular la relación entre bienes que son "objetos" a los efectos del instrumento internacional y bienes que no lo son.

80. El Convenio establece una regla general, en sede de prioridad, aplicable a todas las categorías de bienes, salvo modificación ulterior en el Protocolo. El Artículo 29.7 establece que "(e) 1 presente Convenio: a) no afecta a los derechos que una persona tenga sobre un elemento, que no es un objeto, antes de la instalación del elemento en un objeto si los derechos continúan existiendo después de la instalación en virtud de la ley aplicable; y; b) no impide la creación de derechos sobre un elemento, que no es un objeto, instalado anteriormente en un objeto, cuando esos derechos se crean en virtud de la ley aplicable". La definición de "objeto" y su extensión objetiva vendrán determinadas por el texto uniforme y no por la legislación nacional. Cada uno de los Protocolos ofrece una descripción del objeto y su extensión según las particularidades de las categorías de bienes. Una comparativa del tratamiento de los accesorios, las partes y los componentes entre los Protocolos ofrece una interesante muestra de la adaptabilidad de las reglas del sistema de Ciudad del Cabo a las prácticas de financiación de la industria y las peculiaridades de los equipos.

81. Bajo el Protocolo Aeronáutico, el concepto de objeto aeronáutico ${ }^{67}$ incluye todos los módulos y otros accesorios, piezas y equipos instalados, incorporados o fijados (por ejemplo, hélices, orde-

\footnotetext{
${ }^{67} \mathrm{Y}$ así suele definirse en los contratos el objeto de la garantía, arrendamiento o reserva de dominio:

"Piezas de la Aeronave: el Fuselaje, cualquier elemento de aviónica, instrumento, unidad, componente, parte, aparato, anexo, accesorio, mobiliario y demás equipamiento, de cualquier naturaleza, que esté instalado sobre la Aeronave, el Fuselaje, en la Fecha de Entrega, o cualquier otro elemento que se suba a bordo, instale o una a la Aeronave, o al Fuselaje."
} 
nadores, o motores instalados en un helicóptero), y todos los datos, manuales y registros relacionados con los mismos. Significa esto que forman parte del objeto al que se incorporan y no puede constituirse sobre ellos independientemente una garantía internacional de acuerdo con el Convenio, sino que siguen la garantía del objeto aeronáutico en la medida que lo integran y aseguran su valor económico. Por ello, en la práctica contractual se regulan con especial cuidado los efectos que la instalación o desinstalación de piezas puede implicar en la preservación de la posición del acreedor garantizado ${ }^{68}$. Sin embargo, en coherencia con el principio de respeto a las garantías nacionales que inspira el texto internacional, el Convenio no afecta a los derechos de garantía creados bajo la ley aplicable sobre un elemento que no sea considerado un objeto y se mantienen estos derechos tras la instalación del elemento en un objeto si así lo prevé la legislación nacional que resulte aplicable (por ejemplo, la reserva de dominio sobre unas hélices incorporadas posteriormente en una aeronave) [Art. 29 (7) del Convenio y Art. XIV (4) del Protocolo que declara la aplicación del artículo del Convenio referido a los elementos, que no sean un objeto, incorporados en una célula de aeronave, un motor de aeronave o un helicóptero]. Supuestos que también se contemplan con detalle en la praxis comercial ${ }^{69}$. Esta regla no sería aplicable, sin embargo, a un motor incorporado en una aeronave porque en virtud del Convenio es considerado un "objeto aeronáutico" independiente a los efectos de la constitución de una garantía internacional separada.

82. La particularidad del Protocolo Aeronáutico es, por tanto, el tratamiento, avalado por la práctica comercial de financiación separada, del motor como un objeto aeronáutico independiente y la desviación así del principio de accesión.

83. En el sector ferroviario, sin embargo, la financiación separada de los motores y otros accesorios no es relevante ni frecuente. Consistente con esta constatación de la industria, el Protocolo Ferroviario (Art. I.2.e) no separa los motores ni otras piezas o elementos instalados y describe con amplitud el concepto de "material rodante ferroviario" que comprende los sistemas de tracción, motores, frenos, ejes, bojes, patines toma-corrientes, partes y cualquier otro componente que esté unido al vehículo o integrado en el mismo, así como los datos, manuales y anotaciones relacionadas. Ninguno de los elementos descritos son objetos a los efectos de la constitución de garantías internacionales.

84. El Protocolo Espacial se desvía de las soluciones de los Protocolos anteriores para atender las especiales características del sector. La enumeración de dispositivos que añade el Protocolo (Art.

${ }^{68}$ M.J. Morillas Jarillo, “Algunos aspectos del leasing de aeronaves en España”, RDM, núm. 208, abril-junio 1993, pp. 471-586, en pp. 517-519.

Así, por ejemplo, en un contrato de leasing de aeronave se establece:

"El Arrendatario también se compromete, hasta la Fecha de Vencimiento y, en su caso, hasta la devolución de la Aeronave al Arrendador, a su propia costa, a sustituir o hacer que se sustituyan lo antes posible, aquellas Piezas que puedan, en su caso, incorporarse, instalarse o unirse a la Aeronave, y que estén, en su caso, desgastadas, se hayan perdido, robado, destrozado, embargado, confiscado, dañado de forma irreparable o hayan devenido inservibles para su uso ordinario, por cualquier motivo, bajo circunstancias distintas de aquellas que impliquen una Pérdida Total. Aquellas Piezas que se retiren de la Aeronave seguirán siendo propiedad del Arrendador, con independencia de donde están situadas, hasta que se sustituyan por una Pieza que se incorpore, instale o una a la Aeronave y que cumpla los requisitos de sustitución de Piezas antes especificados; a partir de dicho momento, las Piezas retiradas dejarán de estar sujetas a los términos de este Contrato, y el derecho de propiedad sobre las mismas pasará al Arrendatario. Salvo que se disponga lo contrario, el derecho de propiedad sobre la Pieza de repuesto pasará inmediatamente al Arrendador en el momento de incorporarse, instalarse o unirse a la Aeronave, y dicha Pieza de repuesto quedará sujeta al presente Contrato y se considerará parte de la Aeronave, a todos los efectos del mismo, en la misma medida que las Piezas que estuvieran incorporadas, instaladas o unidas a la Aeronave en la Fecha de Entrega."

${ }^{69}$ En un contrato de leasing de aeronave, se prevé:

"Cualquier Pieza de repuesto que se incorpore, instale o una a la Aeronave podrá ser propiedad de otra persona, o estar sujeta a una carga en favor de otra persona, o podrá someterse a los contratos de intercambio que sean habituales en la práctica de las compañías aéreas, si el Arrendatario, a su costa, y lo antes posible, (i) transfiere el derecho de propiedad sobre dicha Pieza de repuesto al Arrendador, libre de cargas o (ii) sustituye dicha Pieza por una que sea propiedad del Arrendatario; en ambos casos, la Pieza de repuesto quedará sometida al presente Arrendamiento y será considerada parte de la Aeronave, a todos los efectos, en la misma medida que las Piezas que estuvieran incorporadas, instaladas o unidas a la Aeronave en la Fecha de Entrega. Hasta que esto ocurra, la Pieza retirada y sustituida por la Pieza de repuesto, seguirá siendo propiedad del Arrendador, con independencia de donde se encuentre." 
I.2.k) a la definición de bien de equipo espacial refleja así otra de las particularidades del Protocolo Espacial que lo distingue de los Protocolos Aeronáutico y Ferroviario. Es una enumeración abierta y funcional que permite la constitución de garantías internacionales sobre dispositivos y partes de dispositivos espaciales en el sentido indicado en el artículo. Este amplio alcance de la garantía responde, de un lado, al alto valor económico de algunos de estas partes de dispositivos que justificaría su financiación separada $^{70}$ (como los transpondedores), pero, de otro lado, plantea algunos problemas sobre su adecuada identificación y también para la ejecución de las garantías, si varios dispositivos operan física o funcionalmente conectados ${ }^{71}$, a la vez, que choca con el principio de accesión que en muchas jurisdicciones se aplica a los bienes compuestos.

85. Esta separación del principio de accesión, sin embargo, no es una estrategia propia del Protocolo Espacial, como hemos visto. El Protocolo Aeronáutico ya había optado primero por apartarse de este principio tradicional para reflejar en el concepto normativo de las diversas categorías de bienes las prácticas comerciales de cada industria. En consecuencia, dada esta complejidad, originaria o derivada, funcional y física de los bienes de equipo espacial, el Protocolo recoge expresamente en su Artículo III que los derechos de propiedad o de garantía sobre un bien espacial no se verán afectados por ninguna operación de acoplamiento en el espacio de tal bien a otro bien de equipo espacial ni por la instalación o desinstalación del bien en relación con otro bien de equipo espacial. De este modo, se consiguen articular coherentemente los derechos concurrentes sobre diversos dispositivos, que se califican separadamente como bienes de equipo espacial, pero que forman parte de bienes compuestos sin los efectos del principio de accesión.

86. El nuevo Protocolo MAC también ofrece una interesante solución mixta. Entre los códigos seleccionados para incluir en los Anexos, se han obviado intencionadamente aquellos códigos que contenían exclusivamente partes o complementos. De este modo, se evitaba el riesgo de incluir en el ámbito de aplicación del Protocolo partes, piezas o componentes de escaso valor que no se financian separadamente según las prácticas de la industria. De hecho, únicamente se recoge la referencia a "partes" en el código 871620 y 820713 , pero en ambos casos, aunque las partes y componentes están cubiertas por las categorías más amplias que cubren los códigos superiores de cuatro dígitos (8716, por ejemplo), no se incluyen en las categorías más específicas seleccionadas para los Anexos en forma de códigos de seis dígitos. Tomando en consideración esta exclusión voluntaria de códigos que recojan de forma principal componentes y piezas, independientemente de la denominación con la que un objeto se describa en el Sistema Armonizado (útil, herramienta, implante, accesorio, equipo, elemento de equipo, vehículo, máquina, maquinaria), todo objeto cubierto por un código incluido en el Anexo que corresponda pasa por la mera inclusión a ser tratado como elemento de equipo susceptible de constitución de una garantía internacional. A los efectos del sistema de Ciudad del Cabo, es calificado como "objeto".

87. Otras partes, componentes o accesorios, sin embargo, forman parte del objeto principal a los efectos de la extensión de la garantía o quedan sujetos al Artículo 29 del Convenio cuando resulte de aplicación. Es decir, no son "objeto" de una garantía internacional separada, sino que pasan, según las circunstancias que explicamos a continuación, a ser o no parte del objeto principal y, por tanto, de la garantía internacional sobre el mismo o, por el contrario, a quedar sujetos únicamente a la constitución, en su caso, de garantías sujetas a la legislación nacional no uniforme.

88. Para articular este dispar tratamiento de partes y componentes, en la primera sesión del Comité de Expertos Gubernamentales se completaron las definiciones de cada una de las categorías de equipo agrícola, minero y de construcción (Art. I.2.a, b y h) ${ }^{72}$ añadiendo la precisión de que un objeto,

\footnotetext{
${ }^{70}$ Informe UNIDROIT 2010 - C.G.E. Space Pr./5/W.P.5.

${ }^{71}$ Z. Yun, "Revisiting Selected Issues in the Draft Protocol to the Cape Town Convention on Matters Specific to Space Assets", J.Air L.\& Com., num. 76, 2011, pp. 805-831, en p. 816.

${ }^{72}$ Según la versión publicada en el informe de la primera sesión del Comité de Expertos Gubernamentales celebrada en Roma en marzo de 2017 - UNIDROIT 2017 - Study 72K - CGE1 - Report - Appendix IV, se añade a las tres definiciones:
} 
descrito en un código HS del Anexo, incluirá todo accesorio, parte o componente instalado, incorporado o asociado de algún modo, siempre que no esté cubierto por un código HS separado, así como todos los datos, manuales y registros relacionados ${ }^{73}$.

\section{El Protocolo de Pretoria en el contexto del sistema de Ciudad del Cabo: consistencia con la lógica, los principios y las soluciones del Convenio}

89. El Protocolo de Pretoria es, primordialmente, un componente del sistema de Ciudad del Cabo. Sin perjuicio de las necesarias adaptaciones para acomodar las disposiciones del Convenio a las características propias de los sectores y los bienes - supra III -, y, de las soluciones innovadoras que han debido incorporarse en el Protocolo para atender situaciones nuevas, inexistentes en los Protocolos previos, - infra $\mathrm{V}$ - el Protocolo de Pretoria se alinea plenamente con la lógica, los principios y las originales soluciones del Convenio que definen el sistema de Ciudad del Cabo.

90. Por tanto, una garantía internacional sobre bienes de equipo agrícola, minero o de construcción conforme al Protocolo de Pretoria queda sujeta en su constitución, como garantía internacional, uniforme y autónoma ${ }^{74}$, a las sencillas reglas de creación del Convenio, al cuerpo de normas sustantivas uniformes sobre prioridad, remedios en caso de incumplimiento y tratamiento de la garantía en la insolvencia, y a la prioridad que le confiere la inscripción en el Registro Internacional que a tal fin se constituya $^{75}$.

91. La autonomía de la garantía internacional en su constitución y su operativa se logra desconectando su configuración y los requisitos para su nacimiento de la legislación nacional. Para constituir una garantía internacional sobre algunos de los objetos de su ámbito de aplicación, según el Protocolo de Pretoria, basta con un acuerdo de los citados en el Convenio - un contrato constitutivo de garantía, un contrato con reserva de dominio, o un contrato de arrendamiento - que satisfaga los sencillos requisitos del artículo 7 del Convenio. Es absolutamente irrelevante que tal garantía encuentre en el Derecho nacional un equivalente o que cumpla con las condiciones para su constitución bajo la ley aplicable. Es en este sentido en el que se puede proclamar la autonomía del concepto de garantía internacional.

92. De acuerdo con el Artículo 7 del Convenio, el acuerdo deberá constar por escrito, referirse a un objeto sobre el cual el otorgante de la garantía, el vendedor condicional o el arrendador goce de poder de disposición, identificar el objeto de conformidad con el Protocolo y, en caso de un contrato constitutivo de garantía, identificar las obligaciones garantizadas ${ }^{76}$.

93. La autonomía de la garantía internacional no es, sin embargo, plena. La propia existencia del contrato, la capacidad de las partes, la válida emisión del consentimiento y cualquier otra cuestión relativa a su perfección se rigen por la ley aplicable. En particular, el momento en el que se considera

"(...) including all installed, incorporated or attached accessories, components and parts which do not fall within a separate Harmonised System code listed in that Annex, and all data, manuals and records relating thereto"

${ }^{73}$ M. Dubovec, "Accessions and Non-Accessions under the Cape Town Convention: Special Focus on MAC Equipment", Cape Town Convention Journal, Volume 6, 2017, pp. 52-65.

74 A.M. Garro, "El concepto genérico, global e integrado de «garantía mobiliaria»: perspectivas comparadas", op.cit.; R. Goode, "The International Interest as an Autonomous Property Interest”, op.cit.; T. Rodríguez de las Heras Ballell, "El concepto funcional de garantía en el Convenio de Ciudad del Cabo...", op.cit.

${ }^{75}$ La Comisión en pleno de la Conferencia Diplomática adoptó la Resolución num. 1 relating to the establishment of the Preparatory Commission for the establishment of the International Registry for mining, agricultural and construction equipment. Esta Comisión (PrepCom) se encargará de preparar los criterios, condiciones y requisitos para el Registro Internacional del Protocolo de Pretoria.La primera reunión de la Comisión Preparatoria tuvo lugar los días 21 y 22 de mayo de 2020.

${ }^{76}$ Son, por cierto, requisitos muy familiares, en contenido y terminología, para el ordenamiento estadounidense, en concreto, para el Uniform Commercial Code. P.B. Larsen; J.C. Sweeney; J.E. Gillick, Aviation Law. Cases, Laws and Related Sources, Chapter 15. Aircraft Ownership and Financing, Ardsley, Transnational Publishers, 2006, p. 793. 
concluido el acuerdo, dato, sin embargo, relevante para el juego de determinadas disposiciones del Convenio (i.e., Arts. 3, 25 (2) o 60) está determinado por las reglas aplicables de la legislación nacional. No obstante, el Convenio ha tratado de unificar una serie de sencillos requisitos formales nuevamente autónomos e independientes, en todo lo posible, del Derecho nacional. La relativa sencillez de los requisitos puede implicar que una garantía válidamente constituida de conformidad con la legislación nacional constituya también una garantía internacional. En tal caso, ambas garantías conviven, con la salvedad de que, si no se recurre a la inscripción en el Registro internacional, se corre el riesgo de perder la prioridad, y con la advertencia de que ni el deudor ni el acreedor podrán hacer valer derechos reconocidos por la ley nacional que entren en conflicto con el Convenio.

\section{Puntos de interacción, complementariedad y coordinación entre el Protocolo de Pretoria y la legislación nacional}

94. La convivencia de una garantía internacional con una garantía nacional "equivalente" denota que hay puntos de interacción entre el régimen internacional uniforme y la legislación doméstica - no sólo las normas sobre garantías sino también leyes relacionadas como la legislación sobre insolvencia, procesal, registral o notarial -. En el caso del Protocolo de Pretoria estas áreas de interacción son, por diversas razones, algo más frecuentes, intensas y numerosas ${ }^{77}$.

95. Primero, porque una garantía creada sobre un bien de equipo conforme al Protocolo de Pretoria puede constituir simultáneamente una garantía nacional si se cumplen, como puede ocurrir en aquellas jurisdicciones más liberales o laxas en la determinación de los criterios de creación, también los requisitos domésticos para la constitución de una garantía nacional, en cualquiera de sus formas. En estos casos, además, puede ocurrir que la garantía resulte inscrita - y sea conveniente para ciertos fines - tanto en el Registro Internacional como en el registro nacional o local competente.

96. Segundo, porque el propio sistema de Ciudad del Cabo como régimen jurídico internacional uniforme es inevitablemente incompleto. Sus limitaciones y exclusiones han de completarse, integrarse o complementarse por la legislación nacional aplicable. Por ello, es fundamental para lograr un pleno aprovechamiento de los beneficios que derivan de la adopción del sistema de Ciudad del Cabo no sólo que la implementación sea adecuada y efectiva ${ }^{78}$, sino además que el marco legislativo nacional sea moderno y esté alineado con los principios internacionales ${ }^{79}$.

97. En el caso del Protocolo de Pretoria, se identifican tres grandes áreas donde la interacción con la legislación nacional aplicable es más clara, más intensa y más frecuente: el ámbito objetivo de aplicación, las cuestiones relacionales con la inscripción registral y las disposiciones originales del Protocolo sobre inventario y equipos asociados a bienes inmuebles.

77 T. Rodríguez de las Heras Ballell, "The interaction between the MAC Protocol to the Cape Town Convention and domestic law", Butterworths Journal of International Banking and Financial Law, vol. 35, issue 2, 1 february 2020, pp. 112-116. ISSN: 0269-2694. Citation: (2020) 2 JIBFL 75, pp. 112-116.

78 T. Rodríguez de las Heras Ballell, "Key points for the effective implementation of the Cape Town Convention: the accession of Spain to the Aircraft Protocol", Uniform Law Review - Revue de droit uniforme, vol. 21, issue 2-3, 2016, pp. 279308, DOI: https://doi.org/10.1093/ulr/unw01.

${ }_{79}$ Sobre la conformación de un conjunto de principios internacionales para un Derecho de garantías mobiliarias moderno, C.W. Mooney, "Lost in Transplantation: Modern Principles of Secured Transactions Law as Legal Transplants" (April 22, 2020), en L. Gullifer \& N. Dora (Eds.), Secured Transactions Law in Asia: Principles, Perspectives and Reform, Hart Publishing, 2020 (en prensa). Desde la perspectiva de estos principios internacionales, un estudio, en la misma obra, sobre la modernización y reforma de los sistemas de garantías mobiliarias en los sistemas de civil law en T. RODRÍGUEZ DE LAS HERAS Ballell "Secured Transactions Law Reform in Civil Law Jurisdictions: Challenging Tradition, Facing Reality, and Embracing Modernity”, en L. Gullifer \& N. Dora (Eds.), Secured Transactions Law in Asia: Principles, Perspectives and Reform, Hart Publishing, 2020 (en prensa). 
98. En la delimitación del ámbito de aplicación, la original fórmula del Protocolo de Pretoria hace inevitable asumir que habrá operaciones de financiación de equipos habitualmente empleados en actividades mineras, agrícolas y de construcción que habrán de regirse por la legislación nacional aplicable, porque sencillamente no está cubiertos por los códigos HS de los Anexos - además de partes, componentes o accesorios no instalados; derechos de crédito; o, naturalmente, garantías pre-existentes creadas antes de la entrada en vigor del Protocolo (Art. 60) -. Esto implicará que, si se planifica una operación de financiación sobre una empresa en su conjunto o sobre un pool de diversos activos del deudor, los contratos pueden quedar sujetos a diversos regímenes. El acreedor deberá entonces valorar cómo gestionar esta dualidad de regímenes. El objetivo de simplificar normativamente la operación podría aconsejar sujetar la operación en su conjunto a la legislación nacional, renunciando a los beneficios del régimen uniforme. Pero, la pérdida de prioridad que implica no aplicar las reglas del Protocolo de Pretoria a aquellas categorías de bienes cubiertas por el texto uniforme es, sin duda, un elemento crítico que inclinaría la balanza en un sentido contrario y claramente favorable a la opción por el régimen uniforme.

99. La delimitación clara del ámbito de aplicación objetivo del Protocolo de Pretoria en una operación de financiación compleja con múltiples activos será también crítica para planificar la inscripción. Ciertas consideraciones asociadas a la legislación nacional - sanciones por no inscripción, ejercicio de remedios, determinación de fechas de devengo o vencimiento - podría llevar a las partes a tener que proceder a una inscripción duplicada de la garantía internacional (Registro Internacional y registros nacionales o locales). Una situación que no siendo, en términos generales, patológica, puede, sin embargo, añadir costes significativos a la operación sin aportar grandes beneficios jurídicos en términos de prioridad, eficacia en la ejecución y reconocimiento de la garantía. Esta consideración es especialmente relevante si recordamos que la inscripción en el Registro Internacional no sólo es altamente eficiente en términos de agilidad, costes y alcance de sus efectos, sino que además no es un requisito para el ejercicio de los remedios y acciones en caso de incumplimiento por el deudor. Es decir, que el acreedor garantizado (vendedor con reserva de dominio, arrendador) podrá ejercitar los remedios del Convenio y el Protocolo incluso con respecto a una garantía internacional no inscrita en el Registro Internacional.

100. Finalmente, la tercera área de interacción más evidente entre el Protocolo de Pretoria y la legislación nacional aplicable es la que se activa cuando un Estado Contratante realiza alguna de las declaraciones prevista en el texto internacional. Estas declaraciones, que pueden adoptar la forma de exclusión (opt-out) - Art. VIII, sobre la colaboración de las autoridades administrativas en el ejercicio de los remedios por el acreedor - o de inclusión (opt-in) - Art. XVI sobre la designación de puntos nacionales de acceso al Registro Internacional - y que pueden ser obligatorias u opcionales, implican la aplicación de una solución uniforme prevista en el Protocolo (sobre la ley nacional) - Art. X sobre los procedimientos de insolvencia -, la elección de una de las opciones ofrecidas como alternativas por el instrumento internacional (Art. VII sobre los equipos asociados a un bien inmueble) o, por el contrario, la inaplicación del Protocolo o de alguna de sus disposiciones a una operación que, en ausencia de declaración del Estado, habría estado sujeta al régimen uniforme (Art. XII sobre la financiación de inventario). Por tanto, el juego de declaraciones no sólo personaliza, dentro del perímetro así definido por el instrumento internacional, el régimen uniforme para el Estado declarante, sino que además determina las áreas de posible complementariedad y necesaria coordinación entre el texto internacional y la legislación doméstica.

\section{Continuidad y consistencia con los Protocolos previos y algunos ajustes y novedades del Proto- colo de Pretoria}

101. Como componente del sistema de Ciudad del Cabo, el Protocolo de Pretoria se conforma bajo la lógica del Convenio y preservando en todo lo posible y necesario la consistencia con los principios, conceptos y soluciones definitorias del modelo uniforme. Este objetivo de coherencia y conti- 
nuidad hizo emerger, durante el proceso de elaboración, como en Protocolos anteriores, pero de forma más intensa en este caso dada la experiencia acumulada desde la adopción del Convenio y el Protocolo Aeronáutico en 2001, una discreta tensión entre la conveniencia de mantener la redacción de las disposiciones muy próxima a los Protocolos previos y la necesidad de retocar o depurar el texto en aquellos puntos donde se habían detectado insuficiencias o simples aspectos susceptibles de mejora. La primera variable aconsejaba mantener una alta consistencia formal con los Protocolos previos. Hacer cambios de redacción que no estuvieran motivados por necesidades sustantivas podría interpretarse, no obstante, como un cambio intencionado que animara a desviarse de concepciones o interpretaciones previas. La segunda variable alentaba, sin embargo, a aprovechar la oportunidad para mejorar la redacción o aclarar la comprensión de términos, expresiones o formulaciones del texto donde pudiera ser útil y necesario.

102. Se logra en el texto final del Protocolo de Pretoria un resultado de equilibrio muy satisfactorio respetando la consistencia formal y sustantiva con el sistema de Ciudad del Cabo en su conjunto para asegurar la coherencia del modelo uniforme, y limitando los ajustes y desviaciones a aquellos aspectos en donde, bien la continuidad de los Protocolos previos podría conducir a error o a una solución inadecuada para los sectores MAC, o bien era necesario acomodar las reglas a las peculiaridades de los equipos, las características de los sectores, o las prácticas de financiación.

103. Pero, además, en el proceso de deliberación y negociación del Protocolo de Pretoria, en las sesiones del CEG y finalmente en la Conferencia Diplomática, algunas disposiciones fueron objeto de discusión por los Estados, resultando en una modificación apreciable con respecto a las disposiciones equivalentes en los demás Protocolos sin que respondiera al tratamiento de una cuestión nueva. Nos detenemos en tres de estos casos especialmente ilustrativos (Arts. VIII, X y XVI).

\section{A) La nueva declaración en el Artículo VIII sobre remedios en caso de incumplimiento}

104. El primero de los supuestos se refiere al Artículo VIII que contiene ciertas modificaciones del Protocolo a las disposiciones del Convenio relativas a los remedios en caso de incumplimiento. Por ello, es preciso contextualizar primero esta disposición del Protocolo en el marco de los remedios en caso de incumplimiento regulados en el Convenio.

105. La primera de las piezas básicas del régimen jurídico uniforme que configura el Convenio para las garantías internacionales consiste en un conjunto de medidas y derechos a favor del acreedor garantizado (vendedor condicional o arrendador, según los casos) para tutelar su crédito en caso de que concurran ciertos supuestos cualificados.

106. El principio de autonomía de la voluntad domina, en primer lugar, todo el sistema del Capítulo III del Convenio bajo la rúbrica "Medidas ante el incumplimiento de las obligaciones" (Art. 11). Será el acuerdo (por escrito) entre el acreedor y el deudor el que defina los supuestos que se consideran incumplimiento o que, no siéndolo estrictamente, permitan la aplicación de las medidas y el ejercicio de los derechos regulados en los Artículos 8 a 10 y 13 del Convenio (más los específicos previstos en cada Protocolo). Por tanto, los supuestos acordados por las partes, en el momento de concluir el contrato, que activan la aplicación de las medidas y el ejercicio de los derechos correspondientes al acreedor no se reducen al estricto incumplimiento de las obligaciones, sino que pueden incluir cualquier otra eventualidad que implique, al parecer de las partes, una redistribución de los riesgos (i.e. la insolvencia del deudor o un cambio del socio o de los socios de control de la compañía deudora).

107. En el caso, ciertamente inusual, de que las partes no determinen estos supuestos en el contrato, el Convenio (Art. 11.2) cualifica el incumplimiento a los efectos de la aplicación de las medidas y el ejercicio de los derechos establecidos en los Artículos 8 a 10 y 13 del Convenio (además de lo específicamente previsto al respecto en los Protocolos) como "sustancial" en el sentido de que prive 
sustancialmente al acreedor de aquello que tiene derecho a esperar en virtud del contrato, en el momento de su conclusión, no en atención a circunstancias posteriores. Se recurre así a una expresión ya conocida en los textos internacionales, en particular, en el particular concepto sui generis que la Convención de Viena elabora de "cumplimiento esencial" (Art. 25 Convención de Viena), aunque sin añadir la previsión de que la parte que haya incumplido no haya previsto tal resultado y que una persona razonable de la misma condición no lo hubiera previsto en igual situación, esto es, los estándares subjetivo y objetivo del test de previsibilidad. Supuestos de impago en el tiempo acordado, de cumplimiento tardío si de los términos del acuerdo se deduce que el plazo es esencial, de falta de aseguramiento suficiente del objeto o de disposición no autorizada del objeto son casos típicos de incumplimiento sustancial bajo el Convenio; pero también se contemplan contractualmente como supuestos de "default" el incumplimiento de obligaciones de información o la superación de una determinada ratio de endeudamiento general. Se trata, en definitiva, de evitar que incumplimientos menores o de escasa importancia activen inexorablemente el instrumental de medidas y acciones previstas. De hecho, en la práctica comercial, los pequeños incumplimientos suelen conducir a las partes a la renegociación, pero raramente a la resolución del contrato. De este modo, la determinación convencional de los supuestos de incumplimiento actúa como mecanismos de control entre las partes y de seguimiento de la relación contractual.

108. Para la aplicación de las medidas y el ejercicio de los derechos reconocidos a favor del acreedor garantizado (vendedor condicional o arrendador) no es preciso, como ya mencionamos, que la garantía internacional esté inscrita en el Registro Internacional; que es, sin embargo, un requisito previo para asegurar la prioridad de la garantía. La inscripción está destinada fundamentalmente a dar noticia (give notice) a los terceros de la garantía internacional y, en consecuencia, anudar a esta publicidad una serie de efectos en materia de prioridad. El registro, sin embargo, no afecta a la aplicación de las reglas sustantivas que establecen los remedios del acreedor en caso de incumplimiento o de ocurrencia de otras eventualidades así determinadas. La inscripción aporta oponibilidad frente a los terceros, pero no afecta a los efectos inter partes del contrato.

109. La estructura a la que responde el Capítulo III del Convenio es claro reflejo del particular modelo circular, en dos niveles y de base funcional con el que definíamos la opción regulatoria del texto internacional al establecer el concepto de garantía internacional y determinar su ámbito de aplicación. En efecto, tras haber calificado el acuerdo de garantía según las categorías del Derecho interno aplicable, se vuelve al texto internacional para aplicar el régimen sustantivo uniforme de la garantía internacional consistente en un conjunto de medidas ante el incumplimiento, disposiciones para situaciones de insolvencia y unas reglas básicas de prioridad. Pero, a pesar de la deseada uniformidad, el efecto de la divergente categorización de los acuerdos con función de garantía en el Derecho Comparado, obliga al Convenio a mantener esta disparidad de trato también en sede de remedios del acreedor. De ahí que, de la simple lectura de los artículos 8 a 10 del Convenio, se comprenda que la calificación del acuerdo como constitutivo de garantía, de venta con reserva de dominio o de arrendamiento, no es irrelevante, sino que, bien al contrario, implica la previsión de diversos remedios a favor del acreedor garantizado coherentes con su calificación como titular de un derecho de garantía, o de un verdadero derecho de propiedad.

110. Mientras que dos extensas disposiciones (Arts. 8 y 9) detallan las medidas aplicables al acreedor garantizado, una sucinta provisión (Art. 10) contiene los remedios disponibles para el vendedor condicional o el arrendador. Esta diferente extensión de los artículos dedicados en cada caso refleja claramente que, en realidad, el vendedor condicional y el arrendador en la medida que sean tratados como propietarios, les corresponden las facultades absolutas propias de esta condición. Pero será el Derecho interno el que confirme o discrepe con esta categorización jurídica. De modo que, si la ley nacional aplicable califica el contrato con reserva de dominio como un contrato de garantía y equipara así la posición del vendedor condicional a la de un acreedor garantizado, se aplicarán las medidas establecidas en los Artículos 8 y 9 y no las del artículo 10 . 
111. De acuerdo con el Artículo 8, el acreedor garantizado puede tomar la posesión o el control del objeto gravado en su beneficio, vender o arrendar dicho objeto o percibir los ingresos o beneficios provenientes de la gestión o explotación del mismo. El Artículo 9, a su vez, establece el mecanismo para que se pueda adjudicar al acreedor la propiedad del objeto gravado con el fin de satisfacer así total o parcialmente las obligaciones garantizadas. De estas cuatro medidas, la consistente en arrendar el objeto gravado está sujeta a la eventual declaración de los Estados contratantes prevista en el Artículo 54 (1). De acuerdo con esta disposición, los Estados contratantes podrán en el momento de depositar su ratificación, adhesión, aceptación o aprobación declarar que el acreedor garantizado no podrá arrendar el objeto en su territorio mientras se encuentre situado en su territorio o controlado desde el mismo.

112. De conformidad con el Artículo 10, el vendedor condicional o el arrendador podrán dar por terminado el contrato y tomar posesión o recuperar el control sobre el objeto. Cualquier otra medida, como proceder a la venta o al arrendamiento del objeto, ni necesita consentimiento del deudor, ni implica el derecho de este último a obtener el excedente que resulte de la venta sobre la cuantía de la deuda garantizada. Las partes podrían, no obstante, acordarlo y, en tal caso, así se aplicaría, siempre que no vulnerara algunas de las disposiciones imperativas del Convenio. Conviene además poner en conexión esta disposición con las reglas de prioridad del Convenio establecidas en el artículo 29 para valorar la posición de los compradores condicionales o arrendatarios con respecto a otras garantías internacionales previamente inscritas (Artículo 29 (4)).

113. Al igual que con respecto a las medidas disponibles para el acreedor garantizado, el Convenio prevé la posibilidad de que las acciones del Artículo 10 se ejerzan extrajudicialmente o mediante la debida orden judicial. Nuevamente es la declaración de los Estados contratantes en virtud del Artículo 54 (2) la que determinará la viabilidad del ejercicio de estas medidas sin intervención judicial.

114. Una vez determinadas las medidas correspondientes a la calificación o recalificación del acuerdo, pueden ser de aplicación otras medidas adicionales previstas en el Protocolo específico, en la legislación aplicable, o acordadas por las partes (Artículo 12 del Convenio). La autonomía de la voluntad de las partes que permitía definir los supuestos de incumplimiento o las demás eventualidades capaces de activar la aplicación de las medidas previstas, se extiende también a la propia determinación de otras medidas adicionales e incluso a la modificación o inaplicación de los efectos de estas disposiciones del Convenio, siempre que no sean contrarias a las disposiciones imperativas del Capítulo III según quedan enumeradas en el Artículo 15. En este último caso, la autonomía de la voluntad no sólo se refiere a los eventuales pactos entre el acreedor y el deudor, en cada tipo de contrato, sino a todo acuerdo entre el acreedor y cualquier otra persona interesada, según se define en el Convenio, para inaplicar o modificar los efectos de las disposiciones del Convenio en sus relaciones recíprocas, salvo aquellas cuya aplicación es imperativa.

115. La ley aplicable puede prever otras medidas adicionales que resultarán aplicables si no contradicen las disposiciones imperativas del Convenio según las detalla el Artículo 15. Además, la legislación nacional vuelve a ser relevante en materia procedimental pues será la ley del lugar en el que tal medida se deba aplicar la que prescriba el procedimiento que deba seguirse en cada caso (tomando en consideración lo previsto en el Artículo 54 (2) del Convenio con respecto a la necesidad de una autorización judicial).

116. Los Protocolos sectoriales, tratando de responder a las especiales exigencias de cada industria, pueden añadir medidas específicas o modificar las disposiciones del Capítulo III de Convenio. Así, el Protocolo Aeronáutico añade en su Artículo IX dos acciones adicionales especialmente adaptadas a la categoría de los equipos gobernados por el mismo: solicitar la cancelación de la matrícula de la aeronave y pedir la exportación y trasferencia del equipo aeronáutico en cuestión del Estado en el que se encuentre situado a otro. De este modo, se permite al acreedor modificar la nacionalidad de la aeronave, de acuerdo con los términos del acuerdo y la legislación aplicable, y solicitar su traslado en consecuencia al nuevo 
Estado de su nacionalidad o, de hecho, a otro Estado. Estas medidas están disponibles para todos los acreedores, esto es, acreedor hipotecario, vendedor condicional o con reserva de dominio o arrendador y, en este sentido, complementan no sólo a los Artículos 8 y 9, sino también al Artículo 10 del Convenio e, incluso, al Artículo 13, puesto que pueden solicitarse, para los objetos aeronáuticos, también como medidas provisionales sujetas a la decisión definitiva.

117. En este contexto es donde se enmarca el Artículo VIII del Protocolo de Pretoria que analizamos. El Protocolo añade (Art. VIII.1) a los remedios previstos en el Capítulo III del Convenio que ya hemos expuesto, la posibilidad de que el acreedor to the extent that the debtor has at any time so agreed and in the circumstances specified in that Chapter, procure the export and physical transfer of equipment from the territory in which it is situated, mientras que el párrafo 5 de este mismo artículo recogía la obligación de los Estados de asegurar la cooperación y asistencia de las autoridades administrativas relevantes a tales efectos para el ejercicio expedito por el acreedor de los remedios de exportación y traslado físico del equipo.

118. Los párrafos 1 a 4 y 6 , en su redacción originaria, se aprobaron sin cambios, pero el referido párrafo 5 del Artículo VIII fue objeto de una intensa y larga discusión que, de hecho, se prolongó varios días de sesiones hasta lograr alcanzar el acuerdo final. Este párrafo ya había planteado dudas en la segunda sesión del CEG (octubre 2017) y, por ello, había quedado en el texto del borrador que se presentaba a la Conferencia Diplomática entre corchetes para consideración del Pleno. La clave de la discusión se refería fundamentalmente a tres aspectos. Dos de ellos eran esencialmente de redacción, pero con relevancia sustantiva, mientras que el tercero afectaba directamente a la permanencia misma del párrafo en el texto final del Protocolo. Para facilitar la explicación de cómo la redacción del párrafo ha evolucionado y ha sido finalmente adoptada, se transcribe a continuación la versión inicial del borrador presentado a la Conferencia Diplomática:

[5. Subject to any applicable safety laws and regulations, a Contracting State shall ensure that the relevant administrative authorities [including but not limited to tax and customs authorities and transport infrastructure authorities] expeditiously co-operate with and assist the creditor to the extent necessary for the exercise of the remedies specified in paragraph 1.]

119. Esta redacción, como se indicaba, planteó tres cuestiones: a). si debía mantenerse la referencia a "safety laws and regulations" o debía sustituirse por una más amplia a "applicable laws and regulations"; b). si debía mantenerse en el texto final la frase indicada entre corchetes precisando, de forma no taxativa, las autoridades administrativas - "including but not limited to tax and customs authorities and transport infrastructure authorities"; c). si debía mantenerse esta disposición en el texto final al crear una obligación internacional para los Estados Contratantes que algunas delegaciones consideraban excesiva, imprecisa en su extensión, o bien, difícil de hacer efectiva en caso de incumplimiento. A ello se opusieron numerosos motivos. El primero es que lanzaba una señal equívoca al mercado al eliminar en el Protocolo MAC una disposición existente en otros Protocolos previos, lo que podría entenderse como, de hecho, un cambio de dirección intencionado en el caso de los sectores MAC. El segundo, porque esta disposición es clave para la eficacia real de los remedios establecidos en el Protocolo a favor del acreedor en caso de incumplimiento del deudor. El acreedor podría ver fácilmente frustrados todos los intentos de ejercicio de los remedios del Protocolo por falta de colaboración de las autoridades administrativas. En particular, se refiere a la posibilidad de desplazar y exportar el equipo objeto de garantía. Este tipo de remedios está sujeto a ciertos controles o trámites administrativos, cuyo bloqueo haría inoperante de facto el ejercicio del remedio.

120. Tras un intenso debate y largas negociaciones, se alcanzó un acuerdo basado en tres pilares. Primero, se mantiene intacta la referencia a "safety laws and regulations" porque opera como una excepción a la obligación del Estado Contratante y, por ello, debe quedar limitada a razones de seguridad. De este modo, se evitaría que, en la práctica, un Estado se amparara en cualquier legislación nacional 
para que las autoridades administrativas no facilitaran la exportación del equipo. Segundo, se elimina la referencia entre corchetes a algunos ejemplos de autoridades administrativas porque se entendía que, al no ser una lista exhaustiva sino meramente ejemplificativa, era incompleta, vaga y podía generar interpretaciones inadecuadas sobre la extensión institucional de la obligación. Tercero, se acuerda mantener la disposición en el texto final del Protocolo. Para ello, se negoció una solución de compromiso tras considerar varias opciones.

121. Las opciones que se barajaron fueron las siguientes. Primera, una declaración opt-in que obligara a los Estados que quisieran declarar la aplicación de esta disposición a realizar una declaración afirmativa. Esta fórmula fue rechazada por varios motivos: complejidad de la ratificación, carga excesiva e innecesaria a la Secretaría de UNIDROIT con la gestión de declaraciones, esencialidad de la disposición que no podría quedar sujeta a la declaración de aplicación de un Estado y el mismo argumento de la equívoca señal al mercado sobre la eficacia de los remedios y la satisfacción de las expectativas de los acreedores. Segunda, una declaración opt-out que permitiera a los Estados que desearan declarar la inaplicación de esta obligación, realizar una declaración en este sentido. Esta fórmula resultaba más coherente con el amplio apoyo de las delegaciones a la preservación de esta disposición. De modo que el desacuerdo minoritario podría gestionarse de forma más eficaz con una declaración opt-out. Tercera, una declaración mixta en la que el Estado que deseara aplicar la declaración (opt-in) pudiera declarar que tal obligación de colaboración de las autoridades administradoras para facilitar de forma expedita la exportación del equipo se llevara a cabo "de conformidad con los principios de no discriminación", de modo que no pudiera implicar ni interpretarse como un trato preferencial o privilegiado para los acreedores garantizados bajo el Protocolo con respecto al resto de acreedores con garantía.

122. La fórmula de compromiso fue la incorporación de una declaración opt-out que permitiera a los Estados que lo desearan excluir la aplicación en su territorio del párrafo 5. Así, el Artículo VIII quedó redactado como sigue:

"5. Subject to any applicable safety laws and regulations, a Contracting State shall ensure that the relevant administrative authorities expeditiously co-operate with and assist the creditor to the extent necessary for the exercise of the remedies specified in paragraph 1.

6. A Contracting State may, at the time of ratification, acceptance, approval of, or accession to this Protocol, declare that it will not apply the preceding paragraph."

123. En este sentido, el Protocolo de Pretoria incorpora una declaración nueva que se desvía del tratamiento dado a esta obligación en el Protocolo Aeronáutico (Art. XIII.4) y Ferroviario (Art. VII.5).

\section{B) La eliminación de alternativas en el Artículo X sobre remedios en caso de insolvencia}

124. El segundo ejemplo afecta a una de las disposiciones económicas más importantes del sistema de Ciudad del Cabo: el Artículo X referido al tratamiento de la garantía internacional en los procedimientos de insolvencia y los remedios disponibles. Antes de explicar el cambio acometido por el Protocolo de Pretoria, conviene ubicar esta disposición en el sistema uniforme en su conjunto.

125. El Convenio parte de la premisa fundamental de que el valor de una garantía se mide finalmente por su efectividad en un procedimiento de insolvencia. Por tanto, un régimen completo y eficaz para las operaciones garantizadas requiere una adecuada y coherente combinación con las reglas aplicables a las situaciones de insolvencia donde concurren los intereses del deudor y de todos sus acreedores, garantizados o no, privilegiados u ordinarios.

126. La regla general es, de acuerdo con el Artículo 30 del Convenio, que en cualquier procedimiento de insolvencia contra el deudor (o el cedente según Art. 37), la garantía internacional inscrita en 
virtud del Convenio con anterioridad al inicio de dicho procedimiento - según el momento que determine la ley concursal aplicable (Art. 1(d)) - será efectiva, es decir, se reconocerá a su titular la acción de ejecución o realización forzosa de la garantía sobre el objeto afecto quebrando el principio par conditio creditorum. Este reconocimiento se extiende a los derechos y garantías no contractuales inscritos de conformidad con el Artículo 40 y las garantías nacionales protegidas mediante inscripción de un aviso en el Registro Internacional en virtud del Artículo 50 (2).

127. Esta declaración no implica sensu contrario la inmediata y automática negación de todo efecto en el procedimiento de insolvencia a las garantías internacionales no inscritas. En su apartado segundo, el artículo 30 advierte que no perderá eficacia en caso de insolvencia del deudor una garantía internacional no inscrita antes del inicio del procedimiento correspondiente si la ley aplicable nacional le reconoce (al equivalente de la garantía internacional en el Derecho interno) tal eficacia sin necesidad de previa inscripción. Con todo, una garantía internacional no inscrita siempre es más vulnerable a la ley concursal aplicable que una garantía internacional inscrita.

128. Sin embargo, el Artículo 30 (3) del Convenio puede ser modificado por los Protocolos. Así resulta del complejo Artículo XI del Protocolo Aeronáutico que ofrece un régimen especial para los objetos aeronáuticos en los procedimientos de insolvencia en línea con las modernas estrategias de financiación en la industria. Su aplicación depende de la previa declaración del Estado Contratante, en la medida que actúe como jurisdicción principal en el procedimiento concursal, y es susceptible de exclusión (no modificación), en su integridad, por voluntad de las partes (Artículo IV (3) del Protocolo). Esta disposición, considerada una de las de mayor relevancia económica del instrumento y redactada bajo una fórmula alternativa, opera en relación con el Artículo XXX en virtud del cual "(u)n Estado Contratante podrá declarar en el momento de la ratificación, aceptación o aprobación del presente Protocolo, o en el de la adhesión al mismo, que aplicará íntegramente la Alternativa A o íntegramente la Alternativa B del Artículo XI y, en tal caso, especificará los tipos de procedimiento de insolvencia (o "situaciones de insolvencia"), si corresponde, a los que se aplicará la Alternativa A y los tipos de procedimiento de insolvencia, si corresponde, a los que se aplicará la Alternativa B. Un Estado Contratante que formule una declaración en cumplimiento de este párrafo especificará el período requerido en el Artículo XI". El plazo al que se refiere el Artículo XI es el denominado "periodo de espera". De conformidad con la Opción A, en una situación de insolvencia, el administrador de la insolvencia o el deudor, harán entrega del objeto aeronáutico al acreedor garantizado en ese plazo o, si fuera más breve, en el plazo en el que el acreedor hubiera tenido derecho a la posesión del objeto aeronáutico de conformidad con la ley aplicable, distinta del Convenio y el Protocolo.

129. El Protocolo Espacial adopta exactamente la misma fórmula alternativa con dos opciones (Alternativa A y B) y de igual contenido que en el Protocolo Aeronáutico para los bienes de equipo espacial (Art. XXI del Protocolo Espacial).

130. Sin embargo, el Protocolo de Luxemburgo ofrece en este caso una respuesta propia, seguida posteriormente también por el Protocolo MAC en sus etapas iniciales de elaboración, pero que luego descarta. El Artículo XI del Protocolo Ferroviario - y con posterioridad la primera versión del Artículo $\mathrm{X}$ del MAC Protocol - quiebra la dualidad de alternativas sobre la que se construyó el régimen de insolvencia en el Protocolo Aeronáutico para añadir una tercera opción (Alternativa C) que actúa como vía intermedia entre el modelo para riguroso o estricto de la Alternativa A (rule-based) y el discrecional de la Alternativa $\mathrm{B}$. La nueva alternativa retiene los elementos básicos de protección del acreedor que vertebran la Alternativa A, pero con el reconocimiento de una mayor discreción del tribunal para suspender la reposesión del bien por el acreedor en ciertas circunstancias.

131. Los tribunales de los Estados Contratantes aplican estos artículos de los respectivos protocolos de conformidad con la declaración formulada por el Estado Contratante siempre que sea la jurisdicción de insolvencia principal. Si un Estado Contratante no formula declaración alguna, el artículo 
referido no se aplicará y será, por tanto, la legislación concursal nacional la ley aplicable a los supuestos de insolvencia.

132. En este contexto y con estos antecedentes, el Artículo X del Protocolo de Pretoria llega a la Conferencia Diplomática emulando el Protocolo Ferroviario con tres alternativas. Sin embargo, durante las sesiones, se plantea un intenso debate sobre la adecuada configuración de esta pieza clave del sistema de Ciudad del Cabo que termina conduciendo a una importante reformulación del artículo.

133. Este debate arranca con la constatación y el acuerdo sobre la relevancia del Artículo $X$ sobre los remedios en caso de insolvencia para lograr los beneficios económicos del sistema de Ciudad del Cabo. Su esencialidad se condensa en tres principales motivos. Primero, la insolvencia representa el test de stress más importante sobre la efectividad de la garantía mobiliaria y define de forma crucial las expectativas de recuperación del valor del acreedor. Segundo, el equivalente a esta disposición en el Protocolo Aeronáutico, en su Alternativa A, es una de las "qualifying declarations" necesarias para obtener el "descuento del Convenio de Ciudad del Cabo" de la OCDE en la financiación. Tercero, la Unión Europea ha declarado en relación con el Convenio y los Protocolos previos que los Estados Miembros no podrán realizar ninguna declaración relativa a esta disposición que queda bajo su competencia exclusiva. Por tanto, únicamente podrán realizar la reforma de su Derecho interno para incorporar, en su caso, una solución equivalente a la Alternativa A del Protocolo Aeronáutico para obtener los beneficios económicos del descuento ${ }^{80}$.

134. Teniendo en cuenta la situación anterior, el debate sobre el Artículo $X$ del Protocolo MAC se abordó desde la perspectiva de su utilidad económica. La Alternativa A (del Protocolo Aeronáutico) es la única que proporciona beneficios económicos, y ha sido elegida por todos los Estados, salvo uno, que han realizado una declaración. La experiencia demuestra que una eventual elección de las Alternativas $\mathrm{B}$ y $\mathrm{C}$ que, en realidad, no coinciden plenamente con ningún régimen de insolvencia existente, crea una complejísima interacción y resulta de muy difícil ajuste con el Derecho nacional sin proporcionar ventajas económicas. Y, además, puesto que aquellos Estados que no realizan ninguna declaración bajo el Artículo X aplican su Derecho interno las alternativas B y C no tenían ningún valor real en la práctica.

135. Con estas consideraciones se abrió el debate sobre la conveniencia, en tal caso, de eliminar las Alternativas $\mathrm{B}$ y $\mathrm{C}$ del Artículo X dejando como única opción la elección entre la Alternativa A (expresa declaración opt-in) o el Derecho de insolvencia nacional aplicable. Al ser una de las disposiciones en la que los Estados Miembros no tienen competencia y, por tanto, no pueden realizar ninguna declaración, se recordó que la única opción para los Estados Miembros de lograr los beneficios económicos era reformar el Derecho interno. Por tanto, las Alternativas B y C no eran relevantes ${ }^{81}$. La exigencia de la Unión Europea era que la disposición se mantuviera como una disposición opcional sujeta a declaración.

136. Por tanto, a diferencia de los tres Protocolos anteriores que cuentan con una disposición alternativa sobre insolvencia (con dos o tres opciones), el Protocolo de Pretoria contiene un Artículo

\footnotetext{
${ }^{80}$ Efectivamente, el paquete de declaraciones que habilitan para aprovechar una reducción en el coste de la financiación en los términos del ASU (Aircraft Sector Understanding (versión de 1 de febrero de 2017) incluye declaraciones referidas a los Artículos X y XI del Protocolo Aeronáutico, en particular, para la fijación de un plazo para la adopción de medidas provisionales previstas en el Artículo 13 del Convenio. La única vía entonces sería la adaptación del Derecho interno para proveer soluciones funcionalmente equivalentes a las ofrecidas por las declaraciones no disponibles. 1 February 2017 Arrangement on Officially Supported Export Credits [TAD/PG(2017)1] que reemplaza la versión previa de 1 de febrero de 2016, Annex III, Sector Understanding on Export Credits for Civil Aviation (ASU) 1] disponible, junto con información y documentación adicionales en http://www.oecd.org/tad/xcred/aircraftsectorunderstandings.htm.

Lista de países que cumplen las condiciones previstas en los Artículos 35 y 38 del Apéndice II del ASU y que, por consiguiente, resultan cualificados para obtener el descuento del Convenio de Ciudad del Cabo: http://www.oecd.org/tad/exportcredits/ctc.htm.

${ }^{81}$ En la sesión del 14 de noviembre, se aprobó la eliminación de las Alternativas B y C del Artículo X (DCME-MAC-Doc. 24).
} 
$\mathrm{X}$ singular que, manteniendo su naturaleza opcional que requiere la declaración de los Estados para su aplicación (opt-in), sólo cuenta con una única alternativa coincidente con la antigua Alternativa A.

\section{C) Los puntos nacionales de acceso al Registro Internacional}

137. El tercero de los cambios que vamos a abordar se refiere precisamente al tercer pilar en el que, junto con el concepto uniforme y autónomo de garantía internacional y el conjunto de reglas sustantivas uniformes, se apoya el sistema de Ciudad del Cabo: la creación de un Registro Internacional.

138. Con la misma filosofía Convenio general/Protocolos específicos, se prevé la creación de un Registro para cada categoría de bienes. Actualmente, sólo el Registro Internacional para equipo aeronáutico es plenamente operativo y ha alcanzado un éxito indiscutible ${ }^{82}$. Bajo la supervisión de la ICAO, la compañía Aviareto, Limited, con sede en Dublín, opera como registrador del Registro Internacional de equipo aeronáutico. El acceso, la consulta, la inscripción y los demás detalles del funcionamiento del Registro se regulan en su Reglamento de Normas y Procedimientos, así como, al ser íntegramente electrónico, en los Términos de Uso del sitio (www.internationalregistry.aero). Los Registros Internacionales para los Protocolos Ferroviario, Espacial y de Pretoria se encuentran en diferentes fases de concepción y desarrollo funcional y operativo ${ }^{83}$. De hecho, la dependencia de las reglas sustantivas del Convenio/Protocolo del sistema registral exige una plena coordinación entre la entrada en vigor del Protocolo y la puesta en marcha del Registro correspondiente puesto que el sistema sustantivo de Ciudad del Cabo requiere la pieza registral para desplegar todos sus efectos.

139. La función del Registro es dar noticia (notice registration sin aportación documental), asegurar la oponibilidad a terceros y permitir el juego de las reglas de prioridad de las garantías internacionales y otros derechos y acuerdos susceptibles de inscripción (no sólo garantías internacionales, garantías internacionales futuras, cesiones y cesiones futuras de garantías internacionales, adquisiciones de garantías internacionales por subrogación legal o contractual y acuerdos de subordinación de rango, sino también avisos de garantías nacionales y derechos y garantías no contractuales susceptibles de inscripción). Si bien la correspondiente garantía se perfecciona sin necesidad de inscripción, que no es constitutiva, una vez inscrita en el Registro Internacional es oponible a terceros y adquiere prioridad sobre cualquier garantía inscrita con posterioridad y cualquier garantía no inscrita en el Registro, incluso aunque, e independientemente de que, conociera con anterioridad la existencia de la garantía inscrita posteriormente o no inscrita. Por tanto, la inscripción no es un requisito constitutivo de la garantía (inter partes) sino un elemento para su perfección y oponibilidad frente a terceros ${ }^{84}$.

${ }^{82}$ Alcanzando en 2019 un millón de inscripciones y renovando así el contrato con ICAO para gestionar y operar el Registro Internacional - https://www.aviareto.aero/celebrating-one-million-registrations/ (última consulta 15/6/2020).

${ }^{83}$ En la Resolution No. 1 of the Luxembourg diplomatic Conference on 23 February 2007 se constituye una Comisión Preparatoria (Preparatory Commission - Rail PrepCom) para la puesta en funcionamiento del Registro Internacional para material rodante ferroviario. En 2014 se designa y concluye el acuerdo con Regulis SA (filial de SITA) para la gestión del registro.

En la Resolution 1 relating to the setting up of the Preparatory Commission for the establishment of the International Registry for Space Assets, Anexo II del Acta Final de la Conferencia Diplomática de Berlín, UNIDROIT 2012 - DCME - SP Doc. 43, se fija un plazo de tres años desde la adopción del Protocolo el 9 de marzo de 2012 para la puesta en funcionamiento del sistema registral y la entrada en vigor del Protocolo espacial. En la sesión de diciembre de 2015, la Comisión Preparatoria (Space PrepCom) constituida con este objetivo finaliza la elaboración del Reglamento del Registro. En esta misma sesión se abordó la selección de la entidad encargada del registro y la designación de Autoridad de Supervisión.

Como ya se indicó, en la Resolución num. 1 relating to the establishment of the Preparatory Commission for the establishment of the International Registry for mining, agricultural and construction equipment, se constituye la Comisión Preparatoria para el Protocolo de Pretoria. Esta Comisión (PrepCom) se encargará de preparar los criterios, condiciones y requisitos para el Registro Internacional del Protocolo de Pretoria.

${ }^{84}$ D.B. FurNISH, "The Creation and Notice of Security Interest in Movable Property (Efectos Constitutivos y Declarativos de las Garantías Reales Mobiliarias)”, Uniform Commercial Code Law Journal, vol. 36, num. 1, Summer 2003, pp. 99-121. 
140. No obstante, si bien el Registro es único, centralizado e internacional, se ofrece a los Estados contratantes la posibilidad de que designen uno o varios puntos de acceso al Registro Internacional bajo dos posibles modalidades: punto de acceso directo, que transmite directamente la información de la inscripción al Registro Internacional, o punto de acceso autorizante, que sólo autoriza la transmisión de la información - generalmente con el otorgamiento de un código previo (Unique Authorization Code, UAC) -. Todos los puntos nacionales de acceso designados por los Estados contratantes ${ }^{85}$ que han optado por esta opción hasta la fecha operan en la actualidad como puntos autorizantes.

141. La clave para la estabilidad y consistencia del sistema registral internacional es que la existencia de un punto de acceso nacional no altere los requisitos sustantivos de las garantías internacionales ni los requisitos formales para su inscripción de conformidad con el texto uniforme, ni podrá significar la imposición de procedimientos o requisitos, distintos de los establecidos en el Convenio y el Protocolo que pudieran resultar en la efectiva e injustificada denegación de acceso al Registro Internacional.

142. Sin embargo, los puntos nacionales de acceso no forman parte del sistema del Registro Internacional por lo que quedan regulados por la normativa nacional que resulte aplicable. El establecimiento de reglas de funcionamiento y procedimientos adecuados para el punto nacional de acceso es, no obstante, esencial porque pueden afectar a la inscripción de una garantía en el Registro Internacional $\mathrm{y}$, en consecuencia, al despliegue de los efectos derivados de la inscripción. Tengamos en cuenta que, como regla general y de conformidad con el apartado 12.7 de las Normas y Procedimientos para el Registro Internacional (ICAO Doc 9864, octava edición 2019), en caso de existir un punto de acceso nacional, toda inscripción en el Registro Internacional que eluda los procedimientos previstos por el punto nacional de acceso devendría inválida. De modo que, si se designa un punto de acceso, pero no se articula debidamente su funcionamiento o los procedimientos son inadecuados, las partes podrían ver imposibilitada o retrasada la inscripción de sus garantías con los consiguientes efectos en prioridad y oponibilidad. Por todo ello, si bien, está prevista una excepción a la regla general de invalidez (ap. 12.8 Normas y Procedimientos para el Registro Internacional ${ }^{86}$, el efecto útil del sistema registral de Ciudad el Cabo depende, en tal medida, del funcionamiento de los puntos de acceso nacionales.

143. En este contexto, el cambio analizado se refiere al Artículo XVI que permite a los Estados Contratantes designar uno o varios puntos nacionales de acceso, autorizantes o directos, para la inscripción en el Registro internacional. Es una disposición opcional que se aplica únicamente si el Estado hace una declaración en este sentido (opt-in) y que aparece en todos los Protocolos previos. En particular, en el Protocolo Aeronáutico, a pesar de su limitado uso (12 Estados contratantes en el Protocolo Aeronáutico), se ha considerado una disposición relevante para ciertos países que cuentan con un sistema registral consolidado de ámbito sectorial o general. España ha realizado la declaración en relación con los equipos aeronáuticos designando como punto de acceso autorizante el Registro de Bienes Muebles ${ }^{87}$.

${ }^{85}$ En junio de 2020, doce Estados Contratantes han designado un punto nacional de acceso: Albania, Argentina, Brasil, China, Costa de Marfil, Egipto, España, Estados Unidos de América, Méjico, Emiratos Árabes Unidos, Ucrania y Vietnam.

${ }^{86}$ Normas y Procedimientos para el Registro Internacional (ICAO Doc 9864, octava edición 2019):

“12.8 Una inscripción no es inválida si:

a) en el caso de un punto de acceso autorizante, no se puede obtener un código de autorización en el marco de sus procedimientos; o

b) en el caso de un punto de acceso directo, el uso de ese punto de acceso no está permitido en el marco de sus procedimientos; según los hechos de la transacción con que está relacionada".

${ }^{87}$ Sobre la declaración de España en este sentido y la designación del punto nacional de acceso, T. RodRíGUEZ DE LAS HeRAS BALLell, "El nuevo Reglamento de matriculación de aeronaves civiles y el Convenio de Ciudad del Cabo y su Protocolo sobre garantías internacionales en elementos de equipo aeronáutico", Revista de Derecho del Transporte: Terrestre, Marítimo, Aéreo y Multimodal, núm. 15, 2015, págs. 235-257; T. Rodríguez de las Heras Ballell, "La adhesión de España al Protocolo Aeronáutico del Convenio de Ciudad del Cabo y su implementación: una primera valoración del nuevo Reglamento de Matriculación de Aeronaves", Bitácora Millenium DIPr, núm 2, 2015, pp. 88-112 - Parte I http://www.millenniumdipr.com/ba-29-laadhesion-de-espana-al-protocolo-aeronautico-del-convenio-de-ciudad-del-cabo-parte-i, Parte II: http://www.millenniumdipr. com/ba-30-la-adhesion-de-espana-al-protocolo-aeronautico-del-convenio-de-ciudad-del-cabo-parte-ii; T. RODRÍGUEZ DE LAS 
144. En el CEG algunas delegaciones consideraron que, en el sector minero, agrícola y de construcción, la designación de puntos de acceso tendría menos sentido y propusieron la eliminación. Pero por petición de varias delegaciones, la disposición se mantuvo para su posterior deliberación en Pretoria.

145. En la Conferencia Diplomática, la disposición fue, por eso, objeto de un intenso debate en el que se abordaron varias cuestiones: la conveniencia y la utilidad de los puntos de acceso, la obligatoriedad de su uso, los efectos sobre la validez de la inscripción de un eventual incumplimiento de los requisitos del punto nacional de acceso, el factor de conexión para determinar el punto de acceso competente y los posibles modelos alternativos que la tecnología ofrecía para convertir los puntos de acceso en auténticos intermediarios que aportaran valor a los usuarios y facilitaran la gestión de la información al Registro Internacional sobre equipo minero, agrícola y de construcción.

146. La discusión se organizó alrededor de cinco puntos clave. Primero, que el Protocolo MAC debía permitir a los Estados que realizaran una declaración para designar puntos nacionales de acceso en coherencia con los Protocolos previos y para atender los intereses de algunos Estados. Segundo, que la disposición debería ser sencilla y suficientemente flexible para acomodar modelos tecnológicos, funcionales y operativos innovadores siempre que se mantengan adecuadamente alineados con los principios rectores del sistema de Ciudad del Cabo. Tercero, que debía ser la Autoridad Supervisora la que estableciera los estándares de organización y funcionamiento de estos puntos de acceso para garantizar la consistencia con el sistema de Ciudad del Cabo y su viabilidad. Cuarto, que independientemente de que se concibiera el uso del punto nacional de acceso como obligatorio o como facultativo, era fundamental determinar el factor de conexión -bien en el texto del Protocolo, o bien en el Reglamento-. Quinto, que, a pesar de que la lógica del sistema de Ciudad del Cabo, las explicaciones del Comentario Oficial y las disposiciones del Reglamento del Registro Internacional de equipo aeronáutico así lo determinan claramente, convenía aclarar en el texto del Protocolo que el incumplimiento de los requisitos aplicables a un punto nacional de acceso no podrá afectar a la validez de la inscripción en el Registro Internacional y sólo podrá tener consecuencias eventualmente de Derecho nacional.

147. Las decisiones adoptadas en relación con los cuatro primeros aspectos apuntados no supusieron ningún cambio con respecto a los Protocolos previos. Es decir, se mantuvo la disposición en el texto como optativa sujeta a declaración por los Estados y se remitió al ulterior Reglamento que se adoptara para el Registro Internacional del Protocolo de Pretoria el establecimiento de los estándares aplicables a los puntos nacionales de acceso para que fueran consistentes con el sistema de Ciudad del Cabo. En este sentido, la referencia al factor de conexión (se valoró prioritariamente la situación del deudor en coherencia con el factor de conexión general) se establecería en el Reglamento, sin añadir ninguna referencia en el texto del Protocolo. Por tanto, a pesar del largo debate que sirvió para aclarar, confirmar y facilitar un entendimiento común de los Estados sobre la figura de los puntos nacionales de acceso en el contexto del sistema de Ciudad del Cabo, formalmente, la disposición, en estos aspectos, no se desvió de la contenida en los Protocolos anteriores.

148. El cambio que se quiere destacar es el que derivó del análisis del último punto referido: el efecto que el incumplimiento de los requisitos aplicables al punto de acceso nacional tendría sobre la validez y eficacia de la garantía nacional inscrita. Esta cuestión es crítica porque determina, en realidad, la independencia y la eficacia del Registro Internacional como registro internacional. Por ello, la relación

Heras Ballell, "The accession by Spain to the Cape Town Convention: a first assessment", Uniform Law Review - Revue de droit uniforme 2014; DOI: https://doi.org/10.1093/ulr/unu004, pp. 1-23; T. RodrígUEZ DE LAS Heras BaLlell, "Claves para la aplicación en España del Convenio de Ciudad del Cabo y su Protocolo Aeronáutico: análisis del estado de implementación y cuestiones críticas", Bitácora Millenium DIPr, num. 3-4, pp. 100-127, 2016 (http://www.millenniumdipr.com); T. RODRÍGUEZ DE las Heras Ballell, "The Cape Town Convention and its Implementation in Spanish Law" (Chapter 10), in Kozuka, Souichirou (Editor), Implementing the Cape Town Convention and the domestic laws on secured transactions, Ius Comparatum - Global Studies in Comparative Law, Springer, Switzerland, 2017, pp. 173-195. 
radial con los puntos de acceso nacionales, que atiende a los intereses soberanos de los Estados, debía definirse con absoluta claridad para evitar la quiebra del sistema en sus extremos. La decisión que se ha tomado en el Protocolo de Pretoria es decisiva y contundente. Mediante la inclusión de un nuevo párrafo 3 con el tenor siguiente " 3 . A registration shall not be invalid by reason of being made otherwise than in conformity with any requirement imposed by a Contracting State under paragraph 1", el Protocolo de Pretoria establece de manera explícita la inatacabilidad de la validez de la garantía internacional inscrita en el Registro Internacional por la mera razón de que no se hayan cumplido los requisitos aplicables al punto nacional de acceso impuestos por el Estado declarante. Los motivos por los que esta falta de conformidad puede producirse son variados: bien porque el Estado declarante no ha habilitado, a pesar de la declaración, el punto de acceso; bien porque el punto de acceso no es operativo en la emisión del código de autorización; o bien porque se haya incumplido la solicitud o alguno de los trámites del procedimiento habilitados a tal efecto. Todo ello sin perjuicio de las sanciones o consecuencias jurídicas que puedan resultar aplicables a nivel nacional.

149. Estos tres ejemplos tomados de la redacción y adopción final de los Artículos VIII, X y XVI refuerzan el alineamiento del Protocolo de Pretoria con la lógica funcional y operativa del sistema de Ciudad del Cabo mostrando algunas interesantes desviaciones de los Protocolos previos en disposiciones que se proyectan precisamente sobre tres de los componentes esenciales del sistema uniforme: los remedios en caso de incumplimiento, el tratamiento de la garantía internacional en la insolvencia y el modelo registral para dotar de oponibilidad a la garantía y articular las normas de prioridad.

\section{Las soluciones innovadoras del Protocolo de Pretoria: financiación de inventario y equipos asociados a bienes inmuebles}

150. La necesidad de acomodar el marco general del Convenio de Ciudad del Cabo a las características especiales de los bienes de equipo mineros, agrícolas y de construcción, a las prácticas específicas de financiación en estos sectores y, en general, a las condiciones particulares de estas industrias no sólo implicó hacer algunos ajustes en las soluciones comunes, sino además abordar cuestiones completamente nuevas que no se habían tenido que tratar en los Protocolos previos. Una vez más la posibilidad de encajar estas situaciones novedosas en la lógica del Convenio de Ciudad del Cabo sin comprometer su coherencia ni cuestionar sus principios vertebrales ha demostrado la maleabilidad del sistema de Ciudad del Cabo y su fuerza expansiva como técnica armonizadora de base modular y aproximación sectorial.

\section{De la movilidad a la asociación con bienes inmuebles}

151. La primera de las disposiciones totalmente nueva y singular del Protocolo de Pretoria es el Artículo VII que establece el régimen aplicable a los bienes de equipo asociados a un bien inmueble (immovable-associated equipment $)^{88}$. La conveniencia de incluir esta disposición que es única y original del Protocolo MAC es indudable, pues se pueden producir situaciones de conexión del equipo con un bien inmueble que pueden afectar a la existencia de la garantía internacional, a su prioridad o incluso a la naturaleza del equipo como bien mueble, requisito material para crear una garantía internacional en el sistema de Ciudad del Cabo. En contraste con la movilidad natural del equipo aeronáutico, los activos espaciales, y el material rodante ferroviario, el equipo cubierto por el ámbito de aplicación del Protocolo de Pretoria no solo revela una naturaleza móvil bastante menos visible, sino que además puede carecer totalmente de movilidad y quedar fijado, asociado o de algún modo incorporado a un bien inmueble. La

\footnotetext{
${ }^{88}$ Se define en el Artículo I(2), letra k) del Protocolo de Pretoria como:

"(...) equipment that is so associated with immovable property that an interest in the immovable property extends to the equipment under the law of the State in which the immovable property is situated"
} 
asociación potencial con un bien inmueble refuerza, primero, la imagen estacionaria del funcionamiento de estos equipos y, en segundo lugar, requiere proporcionar una solución totalmente nueva para la que no se contaba con orientación alguna en protocolos anteriores.

152. Las características de los equipos a los que se aplica el Protocolo MAC y su funcionamiento ordinario en el curso de la actividad a la que habitualmente se destinan hacen posible que se produzca o sea necesaria, de hecho, para su operativa, una asociación del bien de equipo con bienes inmuebles, de tal manera que el bien pase a tratarse como bien inmueble y/o que la garantía sobre ese bien de equipo que deviene asociado al bien inmueble deje de existir o quede subordinada a cualquier otro derecho o garantía sobre el bien inmueble. El tratamiento de estas situaciones de conexión, asociación o incorporación, sin embargo, reciben un tratamiento dispar en el Derecho Comparado. Las diversas sensibilidades políticas, consideraciones de soberanía estatal e intereses de protección de la tierra explican que la armonización internacional en este campo sea muy limitada ${ }^{89}$ y subyacen en la dificultad de formular una regla común para los equipos asociados a bienes inmuebles. Una dificultad a la que también se ha tenido que enfrentar el Protocolo de Pretoria y que, ante la disparidad de soluciones, tuvo que resolver, por ello, con una disposición con tres alternativas sujeta a la declaración de los Estados Contratantes.

153. El punto de partida es la definición del término "immovable-associated equipment" para delimitar el ámbito de aplicación del régimen opcional que contiene el Artículo VII sujeto a declaración de los Estados. La definición no se basa ni en factores materiales ni fácticos. No se centra en el grado de vinculación del equipo con el bien inmueble, en su permanencia o en su intensidad, sino que recurre a una variable exclusivamente jurídica con una fórmula referencial al Derecho aplicable. Así, se entenderá por equipo asociado a un bien inmueble aquel sobre el que, por razón precisamente de esta conexión o asociación, se extiende un derecho o interés en el bien inmueble (propiedad o garantía) de conformidad con la ley del Estado en el que el bien inmueble está situado. Esta referencia al Derecho del Estado donde esté situado el bien inmueble sólo es pertinente en esta fase para delimitar conceptualmente la figura, pero no determina las consecuencias jurídicas, que resultarán de la declaración del Estado Contratante al Artículo VII.

154. El régimen aplicable a un equipo asociado a un inmueble está contenido en el Artículo VII. Este Artículo tiene tres alternativas que reflejan adecuadamente las diversas posturas que podrán adoptar los Estados Contratantes. Su aplicación depende de una declaración obligatoria que permite a los Estados optar por una alternativa más favorable a la aplicación del texto internacional (esencialmente A), al Derecho nacional (básicamente C) o intermedia (B). Por ello, si el bien inmueble se sitúa en un Estado no Contratante, el Protocolo no resulta de aplicación, y la cuestión se resolverá por la legislación nacional aplicable.

155. Una de las cuestiones más interesantes sobre el alcance del artículo, objeto de intenso debate en la Conferencia Diplomática, es si este régimen está previsto únicamente para determinar la existencia, continuidad y prioridad de las garantías internacionales creadas con anterioridad a la incorporación del equipo en el bien inmueble (pre-association) o también a la posibilidad de crear garantías internacionales en equipos que ya estuvieran incorporados en una propiedad inmobiliaria (post-association). La redacción inicial era confusa: ceases to exist, continues to exist, is subordinated to...De modo que no parecía aplicable a las situaciones de post-association. Se pidió a la Comisión en la Conferencia Diplomática que acordara si pretendía que esta disposición fuera aplicable tanto a las situaciones de creación de garantías internacionales antes de la asociación como a la creación ulterior de una garantía en un equipo que ya fuera immovableassociated equipment. Así se acordó y se procedió a encargar al Comité de Redacción los ajustes pertinentes. Esta decisión es de gran importancia porque se extiende sobre el concepto mismo de "bien de equipo".

156. La distinción entre la Alternativa A (favorable a la aplicación del Protocolo) y la Alternativa B (que ofrece una solución intermedia) es el estándar utilizado para definir la situación de "asocia-

${ }^{89}$ X. Chen; G. Luo, “The Harmonization of Property Law”, Transition Studies Review, num. 17, 2010, pp. 413-429. 
ción" con el bien inmueble. Mientras que la Alternativa A gira esencialmente sobre un estándar fáctico de separabilidad, la Alternativa B opta por un estándar jurídico de individualidad.

157. Se había decidido en la sesión del CGE que la aplicación de la Alternativa A quedaría limitada exclusivamente a los supuestos en los que el immovable-associated equipment se puede separar del inmueble bajo determinadas condiciones fijando un estándar, de tipo fáctico y carácter uniforme (estándar del Protocolo, no del Derecho nacional), que refleje la idea de que el equipo ha perdido su valor como unidad económica causando un daño sustancial cuya reparación implica costes irrazonables. La redacción final se transcribe a continuación:

"3. If immovable-associated equipment is severable from the immovable property, its association with the immovable property does not affect the application of this Protocol, including the creation, existence, priority or enforcement of any international interest in that equipment. This Protocol does not apply to immovable-associated equipment that is not severable from the immovable property.

4. Immovable-associated equipment is severable from the immovable property only if its estimated value after physical disconnection of the equipment from the immovable property would be greater than the estimated cost of the disconnection and of any restoration of the immovable property."

158. La Comisión tuvo que abordar, además, la propuesta de añadir un nuevo párrafo con una presunción iuris tantum: si el equipo es separable del inmueble en las condiciones indicadas en el momento de creación de la garantía internacional o en el momento de la asociación con la propiedad inmueble continúa siendo separable en un momento ulterior. Se aceptó la propuesta y se redactó como sigue:

"5. If immovable-associated equipment is severable from the immovable property at the time it becomes immovable-associated equipment or the time an international interest in the equipment is created, whichever is the later, there is a rebuttable presumption that it continues to be severable from that immovable property"

159. La Alternativa $B$ incorpora como estándar la pérdida de identidad individual en un sentido jurídico y, por ello, de conformidad con la legislación del Estado en el que se encuentre el bien inmueble al que el equipo se ha incorporado. El primer párrafo remite a la legislación doméstica aplicable la regulación de la creación, la existencia, o la prioridad de una garantía internacional en el bien asociado si éste, al incorporarse al bien inmueble, ha perdido su identidad jurídica individual. Si no es así, es decir, si mantiene su identidad jurídica individual, el siguiente párrafo resuelve el conflicto y la prioridad entre un derecho o garantía en el bien inmueble, que por efecto de la incorporación se extienda al bien de equipo, y una garantía internacional inscrita sobre el bien de equipo. Si el derecho o garantía en el bien inmueble se ha inscrito, conforme a los requisitos exigidos por la legislación nacional del Estado declarante, antes de la inscripción de la garantía internacional sobre el equipo y la asociación del equipo con el bien inmueble se ha producido con anterioridad a la inscripción de la garantía internacional sobre tal equipo, entonces la garantía sobre el bien inmueble tiene prioridad sobre la garantía internacional.

160. La Alternativa $C$ representa la opción por la solución que establezca la legislación doméstica. Esto es, la ley del Estado donde se encuentre el bien inmueble será la que determine si una garantía internacional en un bien de equipo asociado con el bien inmueble se puede crear, continúa existiendo o deja de existir con la incorporación, queda subordinada a cualquier otro derecho o garantía en el bien inmueble o se ve afectada de cualquier otro modo por razón de la asociación.

\section{De la financiación sobre activos a la financiación de inventario}

161. La segunda de las disposiciones enteramente novedosas del Protocolo de Pretoria es el Artículo XII. En el borrador de texto elaborado por el Study Group no se había contemplado esta disposi- 
ción. La propuesta de incorporación en el texto del Protocolo de una disposición relativa a la financiación de inventario se debatió en el plenario del CGE y se redactó en el Comité de redacción (Drafting Committee) en el periodo entre sesiones. El motivo de esta propuesta de incorporación en el texto de reglas relativas a la financiación de inventario se debía fundamentalmente a la constatación en la praxis comercial que, a diferencia de los equipos aeronáuticos, ferroviarios y espaciales, los equipos de minería, agricultura y construcción cubiertos por el Protocolo de Pretoria pueden integrarse en el curso ordinario de los negocios en las operaciones de financiación de inventario de intermediarios, distribuidores o concesionarios. La lógica del sistema de Ciudad del Cabo, como un régimen uniforme para las operaciones de financiación de activos, con un Registro Internacional de "folio real" - la inscripción se hace individualmente para cada equipo y tras su perfecta identificación individualizada - se compatibiliza difícilmente con la inscripción en bloque y la rotación natural de los activos en la financiación de inventario ${ }^{90}$.

162. Por ello, y con esta argumentación de fondo, la propuesta quedó articulada en el borrador para la discusión en la Conferencia Diplomática sobre las siguientes bases. Primera, la inclusión de dos nuevas definiciones en el Artículo II: "dealer" y "inventory". Segunda, una nueva declaración que permitiría a los Estados que deseen realizarla excluir (opt-out) el tratamiento como garantía internacional de las garantías sobre inventario creadas o provistas por un "dealer". De este modo, si el Estado Contratante realizara esta declaración, los acreedores que financien inventario para operadores ("dealers") que venden o distribuyen de otro modo equipo minero, agrícola y de construcción no deberán asumir la carga de inscribir cada uno de los equipos del inventario financiado objeto de venta o leasing por el "dealer" en el curso ordinario de su negocio. Tercera, la modificación de las reglas de prioridad del Convenio, en su artículo 29.3(b) y 4(b), cuando el Estado haya realizado la declaración para contemplar una take-free rule que proteja al adquirente del equipo a través de un intermediario (dealer) en el curso de su actividad comercial.

163. El debate que acompañó la discusión de esta disposición en la Conferencia Diplomática y que dirigió su configuración final en el texto presenta las aristas más críticas del sistema de Ciudad del Cabo cuando se expande a sectores donde las prácticas de financiación sobre activos se desvían de la lógica que vertebra el Registro Internacional. Por ello, es interesante exponer con cierto detalle el debate de fondo.

164. La decisión de política legislativa de permitir la inaplicación del Protocolo por declaración expresa de un Estado Contratante a la financiación de inventario apuntaba a la viabilidad y sostenibilidad misma del sistema. La preocupación principal manifestada en las deliberaciones era que una exclusión general del Protocolo MAC a la financiación de inventario quiebra la uniformidad del sistema, afecta a la continuidad del Registro internacional y debilita la consistencia del Convenio. No obstante, frente a estos riesgos, se reconocía que, para algunos Estados, cuyos regímenes de financiación de inventario son sólidos y funcionan eficazmente, la posibilidad de excluir la aplicación del Convenio y el Protocolo en estos casos y con los límites indicados anteriormente (cuando el dealer es deudor) es fundamental. Precisamente el éxito del Protocolo de Pretoria requiere lograr un equilibrio de estos intereses en tensión. Se confirmó así la aceptación de una fórmula de exclusión (opt-out) expresa mediante declaración para aquellos Estados que lo deseen: se presume la aplicación del Protocolo y la exclusión deba ser expresa y mediante declaración.

"1. This Article applies only where a Contracting State has made a declaration pursuant to Article XXVIII(4).

2. An interest in inventory created or provided for by an agreement under which the dealer is the debtor is not an international interest if the dealer is situated in the Contracting State referred to in the preceding paragraph at the time the interest is created or arises

$(\ldots) "$

90 J.F. RIFFARD, "Sûretés mobilières et stocks: ou l'art et la maniére de résoudre la quadrature du cercle", in S. BAZINAS; O. Akseli (Eds.), International and Comparative Secured Transactions Law: Essays in Honour of Roderick A Macdonald, Oxford, Hart Publishing, 2017, Chapter 9. 
165. Aun habiéndose aceptado la conveniencia de permitir esta declaración de inaplicación, el alcance de la exclusión no era clara. Se planteó así si la exclusión de la aplicación del Protocolo en tales casos debía ser total o sólo debía afectar a las reglas sobre la inscripción de la garantía internacional, de modo que los remedios y el tratamiento de la garantía en caso de insolvencia conforme al Protocolo siguieran aplicándose. Esta postura tenía una lógica interesante pues descargaba al acreedor que financia la adquisición de inventario del único elemento del Protocolo que encarece y complica la transacción: la necesidad de realizar las inscripciones en el Registro Internacional sobre cada uno de los equipos que integran el inventario y, por tanto, cancelar la inscripción en cada rotación de inventario que el curso normal del negocio requiriera. Sin embargo, en la medida en que se iba a configurar como una disposición opcional, si aquellos Estados más interesados en realizar la declaración de inaplicación, en las consultas con su industria, consideraban preferible renunciar a todos los beneficios del Protocolo, la Comisión en pleno apoyó la configuración de la declaración como una exclusión plena y no parcial del texto internacional.

166. La segunda derivada del régimen opcional para la financiación de inventario era la configuración de una regla de take-free en estos casos. Se barajaron varias opciones para su configuración: como una regla general del Protocolo aplicable a todas las garantías internacionales dadas las características de los equipos y las partes contratantes; como una regla opcional sujeta a declaración establecida en el propio Protocolo; como una regla opcional vinculada a la declaración que un Estado realizara para la exclusión del Protocolo en caso de financiación de inventario; o, como una remisión a la regla aplicable para una "garantía equivalente" en el Derecho doméstico. Había que tener en cuenta importantes consideraciones para tomar la decisión: que una regla general en el Protocolo, incluso concebida como opcional, arruinaría el funcionamiento mismo del sistema de Ciudad del Cabo; y que la remisión a la legislación nacional crearía en muchas jurisdicciones una situación de altísima complejidad por la disparidad de reglas en función de la naturaleza de la transacción y la dificultad, o imposibilidad, de encontrar una "garantía nacional equivalente" que permitiera identificar el punto de contacto para elegir la ley aplicable. Ante tales consideraciones, la Comisión en pleno acordó como solución que el párrafo 3 del Artículo XII excluyera la aplicación de las reglas de prioridad correspondientes del Artículo 29 del Convenio con el siguiente tenor:

“3. Article 29(3)(b) and 29(4)(b) of the Convention do not apply to a buyer, conditional buyer or lessee of inventory from a dealer if the dealer is situated in the Contracting State referred to in paragraph 1 at the time that a buyer, conditional buyer or lessee acquires its interest in or rights over the inventory (...)."

167. Finalmente, hubo que resolver otra interesante cuestión para delimitar el alcance del régimen opcional para la financiación de inventario: el factor de conexión. Se planteaba si el factor de conexión para la aplicación de la declaración de exclusión de un Estado debía ser la ubicación del inventario (lex res sitae) o la situación del deudor. Este aspecto generó un intenso y largo debate. El segundo criterio garantizaba la consistencia del factor de conexión con el sistema de Ciudad del Cabo que se fundamenta en la situación del deudor, pues, de hecho, es una respuesta ante la inoperancia de la res sitae en equipos móviles. La ubicación del inventario es además un criterio que puede ser cambiante, difícil de determinar (en tránsito), ajeno totalmente a los elementos de la transacción, o inconsistente con las modernas prácticas comerciales. Por ello, se acordó finalmente el empleo de la situación del deudor como criterio único. De entre los criterios del Artículo 4 del Convenio, se optó por elegir únicamente uno de ellos: el establecimiento principal del deudor.

"4. For the purposes of this Article a dealer is situated in a State where it has its place of business or, if it has more than one place of business in different States, its principal place of business."

168. Por tanto, el estudio en profundidad del proceso de elaboración, negociación y adopción, el 22 de noviembre de 2019, en la ciudad de Pretoria, del cuarto Protocolo al Convenio de Ciudad del Cabo que extiende el exitoso régimen uniforme de garantías internacionales a los equipos de minería, agricultura y construcción nos permite concluir que esta adopción del Protocolo de Pretoria reafirma el éxito, la 
solidez y el acierto de este singular y efectivo sistema de Ciudad del Cabo como un ambicioso, flexible y prometedor modelo de armonización internacional. El interesante proceso de elaboración del Protocolo de Pretoria muestra la flexibilidad del sistema de Ciudad del Cabo y refuerza la afirmación de su fuerza expansiva. La consistencia del sistema de Ciudad del Cabo, su agilidad, su maleabilidad y su adaptabilidad a diversos sectores, categorías de equipos y prácticas de financiación se demuestran no sólo en la capacidad de las disposiciones del Convenio de responder a las necesidades de estos nuevos sectores, que se manifiesta en la continuidad y el alineamiento con los conceptos y principios del sistema uniforme, sino también en la receptividad de las soluciones novedosas, únicas y particulares, que el Protocolo de Pretoria ha incorporado hábilmente al sistema sin comprometer su consistencia y su sostenibilidad. 